\title{
Targeting Neural Endophenotypes of Eating Disorders with Non-invasive Brain Stimulation
}

\author{
Katharine A. Dunlop ${ }^{1,2}$, Blake Woodside ${ }^{1,3,4,5}$ and Jonathan Downar ${ }^{1,2,3,4,6 *}$ \\ ${ }^{1}$ Institute of Medical Sciences, University of Toronto, Toronto, ON, Canada, ${ }^{2}$ MRI-Guided rTMS Clinic, University Health \\ Network, Toronto, ON, Canada, ${ }^{3}$ Department of Psychiatry, University Health Network, Toronto, ON, Canada, ${ }^{4}$ Department \\ of Psychiatry, University of Toronto, Toronto, ON, Canada, ${ }^{5}$ Eating Disorders Program, University Health Network, Toronto, \\ ON, Canada, ${ }^{6}$ Toronto Western Research Institute, University Health Network, Toronto, ON, Canada
}

\section{OPEN ACCESS}

Edited by: Ignacio Obeso, Hospital Universitario Puerta del Sur HM Hospitales, Spain

Reviewed by: Bernd Weber, Rheinische-Friedrich-Wilhelms

Universität, Germany Anne Sauvaget, University Hospital of Nantes, France

${ }^{*}$ Correspondence: Jonathan Downar jonathan.downar@uhn.ca

Specialty section: This article was submitted to Neurodegeneration, a section of the journal

Frontiers in Neuroscience

Received: 17 November 2015

Accepted: 25 January 2016

Published: 16 February 2016

Citation:

Dunlop KA, Woodside $B$ and Downar J (2016) Targeting Neural Endophenotypes of Eating Disorders with Non-invasive Brain Stimulation.

Front. Neurosci. 10:30

doi: 10.3389/fnins.2016.00030
The term "eating disorders" (ED) encompasses a wide variety of disordered eating and compensatory behaviors, and so the term is associated with considerable clinical and phenotypic heterogeneity. This heterogeneity makes optimizing treatment techniques difficult. One class of treatments is non-invasive brain stimulation (NIBS). NIBS, including repetitive transcranial magnetic stimulation (rTMS) and transcranial direct current stimulation (tDCS), are accessible forms of neuromodulation that alter the cortical excitability of a target brain region. It is crucial for NIBS to be successful that the target is well selected for the patient population in question. Targets may best be selected by stepping back from conventional DSM-5 diagnostic criteria to identify neural substrates of more basic phenotypes, including behavior related to rewards and punishment, cognitive control, and social processes. These phenotypic dimensions have been recently laid out by the Research Domain Criteria (RDoC) initiative. Consequently, this review is intended to identify potential dimensions as outlined by the RDoC and the underlying behavioral and neurobiological targets associated with ED. This review will also identify candidate targets for NIBS based on these dimensions and review the available literature on rTMS and tDCS in ED. This review systematically reviews abnormal neural circuitry in ED within the RDoC framework, and also systematically reviews the available literature investigating NIBS as a treatment for ED.

Keywords: Eating Disorders (ED), RDoC, rTMS, tDCS, fMRI

\section{INTRODUCTION}

The term "eating disorders" (ED) encompasses a wide variety of disordered eating and compensatory behaviors that inappropriately alter the patient's body shape or weight, or the subjective experience of one's own body shape or weight. According to recent studies, the lifetime prevalence of EDs is 5.7\% for females, and 1.2\% in males (Golden et al., 2003; Hudson et al., 2007; Smink et al., 2014). The lifetime prevalence of the top three EDs according to the DSM-5 diagnostic criteria is $2.3,1.7$, and $0.8 \%$ for adolescent binge eating disorder (BED), anorexia nervosa (AN), and bulimia nervosa (BN), respectively (Golden et al., 2003; Hudson et al., 2007; Smink et al., 2014). BED is associated with recurrent episodes of binging, typically during negative affect (Leehr et al., 2015), and with the absence of inappropriate compensatory behaviors to avoid weight gain. Both $\mathrm{AN}$ and $\mathrm{BN}$ are associated with disturbances in the subjective experience of one's own body shape or weight; this phenotype is also known as body 
dysmorphia. BN is also defined by recurrent episodes of binge eating, with inappropriate compensatory behaviors to avoid weight gain; such behaviors include vomiting, excessive exercise, laxative misuse or diuretic misuse. In contrast, $\mathrm{AN}$ is defined by the persistent restriction of food, an intense fear of gaining weight, and a significantly low body weight for one's developmental stage. AN has two subtypes, restricting (ANR) and binge-eating/purging (ANBP), with the latter distinguished from the former by the presence of binges and/or purges.

Despite a low lifetime prevalence rate relative to other psychiatric disorders, EDs carry a significant burden of illness, both socially and individually. Treatment capacity in specialized ED programs is presently inadequate to meet demand (Hart et al., 2011), and for patients who do manage to access specialized programs, economic difficulties and high costs often hamper treatment adherence (Gatt et al., 2014). EDs are also associated with a high mortality rate; for one, approximately $10 \%$ of AN sufferers will die within 10 years of disease onset (Sullivan, 1995). According to a recent meta-analysis, the overall standard mortality ratio (SNR) for AN is 5.86, higher than schizophrenia (2.8), bipolar disorder (2.1), and major depression (1.6) (Arcelus et al., 2011). Conventional ED treatments, including pharmacotherapy, and in- and out-patient behavioral therapies, are associated with suboptimal recovery rates ( $\sim 50 \%$ for $\mathrm{AN} ; \sim 45 \%$ for $\mathrm{BN} ; \sim 50-70 \%$ for $\mathrm{BED}$ ), high relapse rates (ranging from 9 to 65\%), and high chronicity ( $\sim 20 \%$ will develop a chronic disorder; Olmsted et al., 2005; Mitchell et al., 2007; Shapiro et al., 2007; Carter et al., 2012; Hay et al., 2012; Hilbert et al., 2012; Amianto et al., 2015). ANBP, in particular, has the poorest prognosis of the eating disorders (Steinhausen and Weber, 2009). EDs are also highly co-morbid with other psychiatric disorders, such as major depression and obsessive-compulsive disorder, whose presence negatively impacts treatment outcomes (Godart et al., 2003; Crane et al., 2007; Mischoulon et al., 2011). Thus, new treatment approaches are urgently needed, especially for the substantial proportion of ED patients who are unresponsive to conventional treatment strategies.

Neuromodulation technologies are beginning to emerge as a promising new treatment option for treatment resistant ED patients. The potential usefulness of these techniques was recently illustrated in a pilot study using subgenual cingulate deep brain stimulation (DBS) to achieve symptomatic improvements in severe and treatment-refractory AN (Lipsman et al., 2013). Although potentially powerful, DBS remains for the moment a fairly invasive treatment, and is available only to small volumes of patients in specialist neurosurgical centers. A more accessible alternative is non-invasive brain stimulation (NIBS), including techniques such as repetitive transcranial magnetic stimulation (rTMS) and transcranial direct current stimulation (tDCS). rTMS uses rapid pulses of an electromagnetic field to elicit action potentials in the target area of cortex. tDCS uses a weaker intensity electrical stimulus, delivered by scalp electrodes, to modulate cortical excitability in the underlying regions. Both NIBS strategies attempt to alter the cortical excitability of a target brain region to normalize particular disorder-specific phenotypes. Cortical targets are typically selected based on abnormal structural or functional attributes in the disorder relative to healthy controls. Appropriate cortical targeting using NIBS is critical for optimal treatment efficacy (Fox et al., 2013). Therefore, a proper understanding of the neural substrates, as well as the cognitive and behavioral phenotypes accompanying these substrates, is crucial for optimizing future treatments.

Two major issues associated with NIBS as a treatment for ED are the tremendous heterogeneity in the cognitive and behavioral phenotypes of patients within this illness category, and the dynamic course of the illness, in which patients can switch from one ED diagnosis to another over time (Garfinkel et al., 1995; Keel and Mitchell, 1997; Lilenfeld et al., 1998; Sullivan et al., 1998; Strober et al., 2000; Bulik et al., 2005; Milos et al., 2005). This variability within a single diagnosis and this malleability of symptoms is a likely contributor to the limited clinical efficacy of NIBS (and in conventional treatments more generally) for ED.

Two possible solutions to address this heterogeneity are genomic methods, such as phenotypic linkage analyses, as well as neuroimaging methods. Such tools stratify patients on underlying behavioral, genetic, and neuropathological dimensions rather than self-reported symptoms alone. Therefore, these tools may be useful to identify the underlying behavioral and neuropathological endophenotypes related to more basic dimensions of behavior, independent of DSM-5 diagnoses. Such analyses and resulting endophenotypes can also be related to the behavioral and circuit-based dimensions of the recently described Research Domain Criteria (Insel et al., 2010) ( $\mathrm{RDoC})$. The $\mathrm{RDoC}$ is a recent strategy aimed at integrating basic neuroscientific knowledge with clinical diagnoses by first describing fundamental behaviors, described below, as dimensions. These dimensions are then used to describe the pathological behaviors of psychiatric disorders. By using the RDoC schema in combination with neuroimaging and phenotypic linkage methods, we may be able to identify sufficient stimulatory targets addressing specific phenotypes such as restrictive behavior or binging, regardless of DSM-5 diagnosis. For NIBS treatments, diagnostic systems must be capable of parsing this heterogeneity using endophenotypes so we may select the optimal stimulation target for a particular behavioral marker, or neural substrate.

Here, we will review NIBS as a treatment for the three most prevalent forms of ED: AN, BN, and BED. First, we will posit candidate dimensions as outlined by the RDoC and their underlying behavioral and neurobiological targets associated with ED as potential candidates for NIBS. Second, we will review the available literature on rTMS and tDCS as possible treatments for ED. Lastly, we will discuss the current limitations of the NIBSED field, and opportunities of future study and development.

\section{GOING BEYOND THE DSM-5 DIAGNOSIS: HOW CAN WE MAXIMIZE EFFICACY?}

As discussed above, one of the major obstacles in ED diagnosis and treatment is the heterogeneity within each diagnostic category; conversely, comparisons of clinical and psychological features across patients suggest that there is significant overlap 
between ED diagnoses (Garfinkel et al., 1995; Lilenfeld et al., 1998; Sullivan et al., 1998; Strober et al., 2000). Compounding this problem is the evolution of the illness, such that patients may transition from one diagnostic category to another over time (Bulik et al., 2005). For example, it is estimated that approximately $50 \%$ of patients initially diagnosed with ANR will develop binge/purge behaviors, and approximately $30 \%$ of $\mathrm{BN}$ patients have a history of AN (Keel and Mitchell, 1997). In another study following DSM-IV-diagnosed AN and BN, only one third of subjects retained their original diagnosis after 30 months (Milos et al., 2005). To improve diagnostic consistency and treatment efficacy may require us to identify more stable, more granular, and more biologically based subgroups, or endophenotypes, within the ED population.

Some classification efforts have focused on a single DSM diagnosis. AN has been subdivided into 3 stable classes based on co-occurring symptoms: fat-phobic ANR, fat-phobic ANBP, and non-fat-phobic ANR (Wildes et al., 2013). BN has been subdivided based on personality attributes (affectiveperfectionistic, impulsive and low-comorbid psychopathology clusters Wonderlich et al., 2005) and based on presenting symptoms (binging, purging, and bingeing-purging, StriegelMoore et al., 2005).

A number of latent class (LCA) and latent profile analyses (LPA) have been performed on symptomatic and personality factors to stratify endophenotypes spanning $\mathrm{AN}$ and $\mathrm{BN}$. One symptom-based LCA found optimal fitting for a 4-group classification. ANR, ANBP/BN, ANR without OCD, and BN with only vomiting as purging were the four groups identified (Keel et al., 2004). Another symptom-based LPA identified 4 ED classes: binging with multiple types of compensatory behavior; binging with only vomiting as compensatory behavior; binging without purging; and low/normal weight with excessive exercise (Eddy et al., 2009).

As evidenced above, there now exist a variety of different proposals for how best to subcategorize ED patients, within and across DSM-5 diagnoses. How, therefore, can we converge upon a system that offers maximum clinical usefulness? One potentially fruitful method would be to better characterize the heterogeneity among ED patients in biological terms, using techniques such as positron emission tomography (PET), electroencephalography (EEG) and magnetic resonance imaging (MRI) to identify distinct neurobiological substrates underlying the different subgroups within ED. Clinical endophenotypes could then be tied to neurobiological substrates, which could in turn serve as targets for individually- or phenotypically-tailored treatment strategies.

Such an approach would also allow us to describe illnesses in dimensional rather than categorical terms. For example, the influential RDoC framework (Insel et al., 2010) includes dimensional constructs such as positive valence, negative valence, cognitive systems, social processes, and arousal and regulatory systems (for a review of how $\mathrm{RDoC}$ dimensions relate to $\mathrm{ED}$ neurobiology, see Wildes and Marcus, 2015, Table 1). Many endophenotypes, previously identified as symptom clusters in the ED population, can be framed parsimoniously as the result of pathology affecting these dimensions, either singly or in combination (Figure 1). An "RDoC formulation" of our ED
TABLE 1 | Overview of the $\mathbf{5}$ Research Domain Criteria domains as adapted from Insel et al. (2010) and Morris and Cuthbert (2012).

\begin{tabular}{ll}
\hline RDoC Domain & Construct \\
\hline Negative valence systems & Active threat/Fear \\
& Potential threat/Anxiety \\
& Sustained threat \\
& Loss \\
& Frustrative nonreward \\
& Approach motivation \\
Positive valence systems & Responsiveness to reward \\
& Reward learning \\
& Habit \\
Cognitive systems & Attention \\
& Perception \\
& Working/Declarative memory \\
& Language \\
& Cognitive/Effortful control \\
Social processes & Imitation/Theory of mind \\
& Social dominance \\
& Facial expression identification \\
& Attachment/Separation \\
Arousal/Regulatory systems & Self-Representation \\
& Arousal \\
& Circadian rhythms \\
& Sleep and wakefulness \\
&
\end{tabular}

endophenotypes carries the advantage of pointing toward specific cognitive processes, neural pathways, neurotransmitter systems, molecular targets, or genes that might be targeted for therapeutic effect. For the purposes of this review, we will confine our discussion to potential novel uses of NIBS to target specific neural pathways that are associated with RDoC constructs, as they relate to specific endophenotypes within the ED population.

\section{RDOC DOMAINS AS ED ENDOPHENOTYPES AND NIBS TARGETS}

For the following section, a systematic review was completed using PubMed (NIH, http://www.ncbi.nlm.nih.gov/pubmed), with searches containing the following terms: first, clinical terms for the three ED diagnoses in this review (bulimia nervosa, anorexia nervosa, and binge eating disorder), and second, $\mathrm{RDoC}$ related terms as discussed in a recent review on $\mathrm{RDoC}$ cognitive systems (Morris and Cuthbert, 2012).

\section{Negative Valence Systems}

Negative valence systems are activated in response to aversive stimuli, and include fear, anxiety and loss-related behaviors. In a recent meta-analysis investigating neural activations for negative and positive affect, negative valence was associated with greater activation in the amygdala and anterior insula (Lindquist et al., 2015). The lateral orbitofrontal cortex (OFC) is also associated with negative valence, particularly during the anticipation and receipt of punishment (Ursu et al., 2008). 


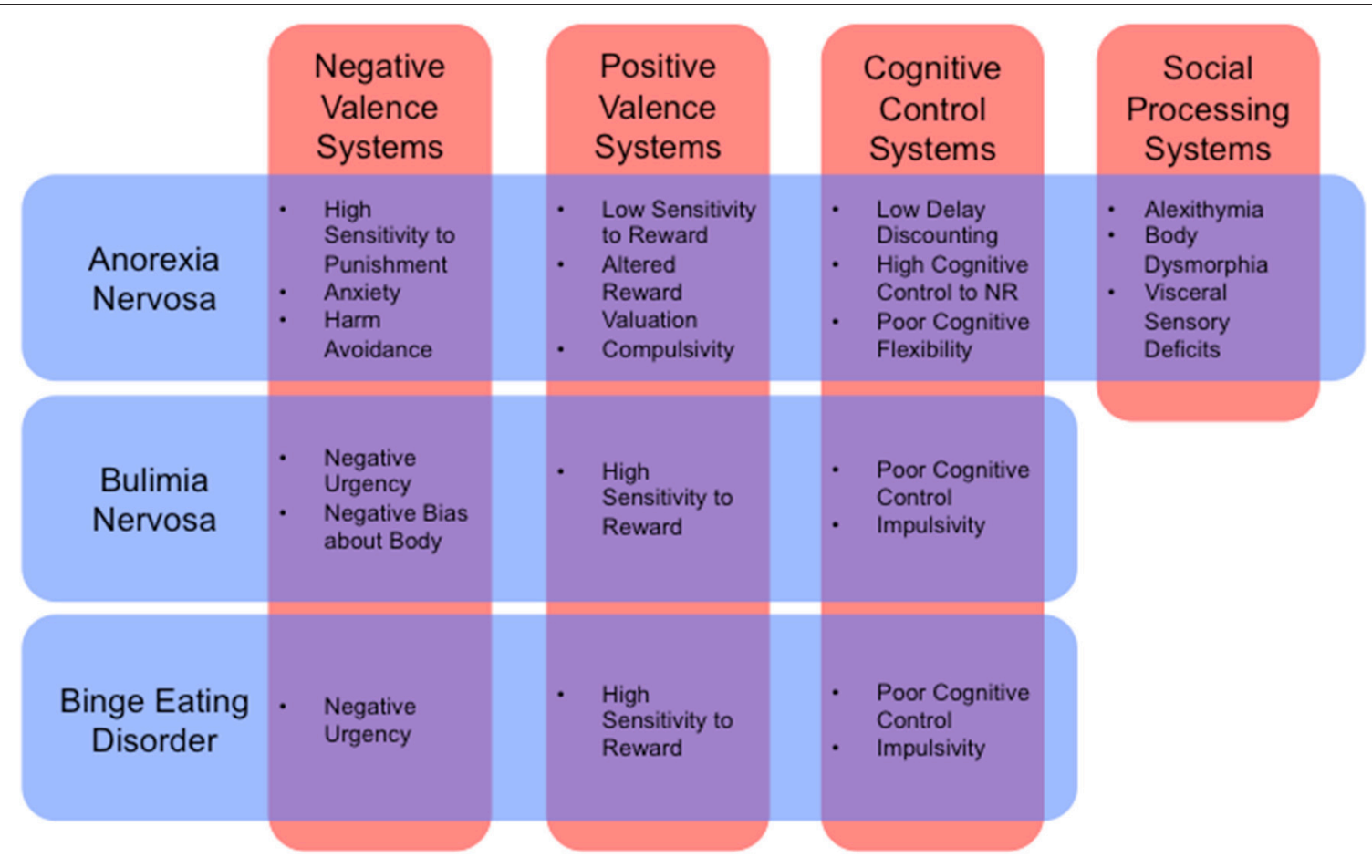

FIGURE 1 | Cognitive and behavioral phenotypes by RDoC dimension (Insel et al., 2010) for anorexia nervosa, bulimia nervosa, and binge eating disorder (Schebendach et al., 2007, 2013; Fernández-Aranda et al., 2008; Zastrow et al., 2009; Harrison et al., 2010; Klein et al., 2010; Miyake et al., 2010; Manwaring et al., 2011; Bohon and Stice, 2012; Hoffman et al., 2012; Steinglass et al., 2012; Chan et al., 2013; Giel et al., 2013; Strigo et al., 2013; Wu et al., 2013; Glashouwer et al., 2014; Kullmann et al., 2014; Mole et al., 2015; Berg et al., 2015; Racine et al., 2015; Tapajóz P de Sampaio et al., 2015). NR, Natural Rewards.

A number of studies support the role of negative valence systems in ED, mainly in behaviors associated with negative affect, sensitivity to punishment, anxiety, harm avoidance, and response to the receipt of punishment (Figure 1). For example, behavioral measures of negative affect and negative urgency are the two most predictive features before a binge episode in both BED and BN (Bohon and Stice, 2012; Berg et al., 2015; Leehr et al., 2015; Racine et al., 2015). On functional neuroimaging, BN patient reported negative affect is related to neural responsivity during the anticipation of a food reward in both the striatum and insula (Bohon and Stice, 2012). This relation suggests that negative affect and food-reward are inappropriately coupled in this disorder. More generally, BN patients also have higher neural responses to negative body image descriptors (Miyake et al., 2010), in areas associated with the regulation and inhibition of fear and emotional processing circuits, including the dorsomedial prefrontal cortex (DMPFC) (Kühn et al., 2011; Åhs et al., 2015). These findings shed light on the role of negative attentional bias in the psychopathology of bulimic-type disorders.

Restrictive subtypes of ED also show hypersensitivity on measures related to negative valence systems. Behaviorally, exaggerated harm avoidance and sensitivity to punishment are typically associated with forms of AN (Harrison et al., 2010). Similarly, on fMRI, AN patients display increased neural activation in right anterior insula and DLPFC during pain anticipation, and exaggerated responses to punishment (pain and monetary losses) in the DLPFC, and the anterior, mid-, and motor cingulate (Bischoff-Grethe et al., 2013; Strigo et al., 2013; Bar et al., 2015). Cowdrey and colleagues also found an exaggerated response to an aversive taste and sight of food in the insula, striatum and ACC (Cowdrey et al., 2011). Traitanxiety is also a common feature of $\mathrm{AN}$, and is associated with the exaggerated activity of fear-related circuits to food and body-related cues. Regions of exaggerated response to symptomprovoking stimuli include the amygdala, hippocampus, insula, ACC, and medial PFC (Ellison et al., 1998; Frank et al., 2002, 2012b; Seeger et al., 2002; Uher et al., 2004; Friederich et al., 2010; Vocks et al., 2010). Finally, at the receptor level, PET imaging reveals increased striatal dopamine binding potential and altered cingulate serotonergic (increased 5-HT1A, but decreased 5HT2A) binding potential is associated with harm avoidance in AN (Bailer et al., 2004, 2007; Frank et al., 2005).

\section{Summary of Potential Negative Valence Targets}

Both bulimic and restrictive-type EDs display some form of negative valence abnormality on behavioral and neuroimaging modalities (Figure 2). In ED with a binging component, it appears that negative affect and food-reward responsivity are intimately coupled via the exaggerated response of the amygdala, insula and DMPFC. Restriction-related EDs display a similar pattern in the amygdala, right anterior insula, DLPFC and mPFC accompanying aspects of harm avoidance and receipt 


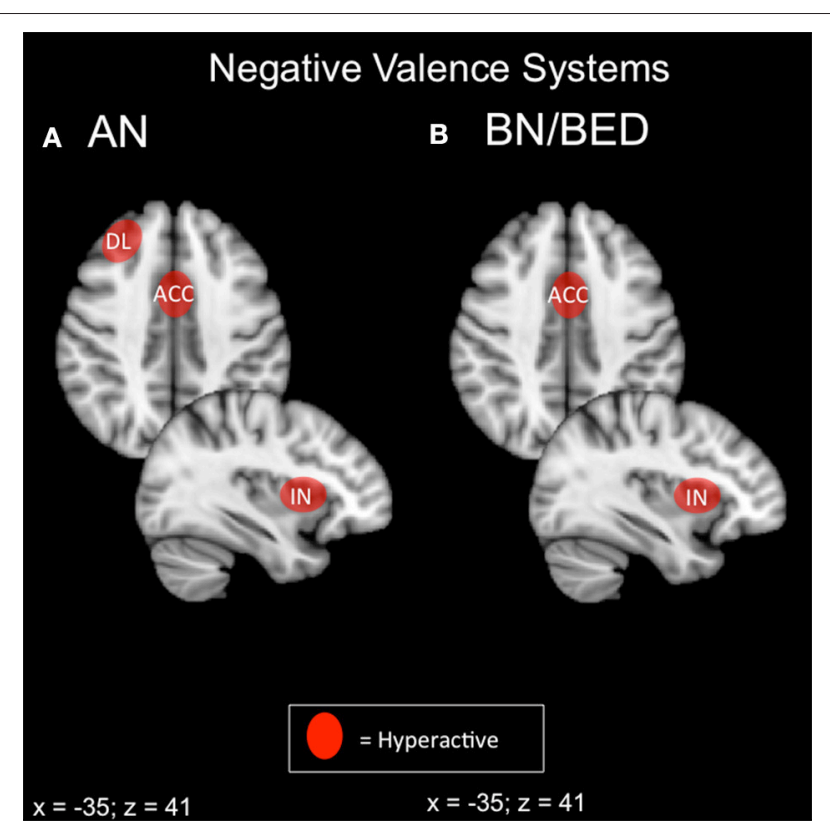

FIGURE 2 | Candidate NIBS targets that address abnormal phenotypes related to the RDoC negative valence dimension. (A) Candidate negative valence NIBS targets for anorexia nervosa (AN) (Ellison et al., 1998; Frank et al., 2002, 2012b; Seeger et al., 2002; Uher et al., 2004; Friederich et al., 2010; Vocks et al., 2010; Cowdrey et al., 2011; Bischoff-Grethe et al., 2013; Strigo et al., 2013; Bär et al., 2015). The dorsolateral prefrontal cortex (DL) is abnormally hyperactive for pain anticipation and the receipt of punishment.

The anterior cingulate cortex (ACC) is hyperactive for aversive food stimuli, the receipt of punishment, and anxiety. Finally, the anterior insula (IN) is abnormally hyperactive during anxiety and the anticipation of pain. (B) Candidate negative valence NIBS targets for bulimia nervosa (BN) and binge eating disorder (BED). The ACC is abnormally activated for negative words about the body (Miyake et al., 2010), while the insula is hyperactive during negative affect (Bohon and Stice, 2012).

of punishment. Frontal regions, particularly the medial PFC and DMPFC, are thought to inhibit activity of the basolateral amygdala (BLA) (Cho et al., 2013; Felix-Ortiz et al., 2015).

Hyperactivation of the DMPFC, DLPFC, and anterior insula during negative valence paradigms has two possible interpretations. First, these areas may be inhibiting BLA activity, but insufficiently, in which case excitatory stimulation may be beneficial. Alternatively, these areas may actually be inappropriately driving BLA activity in a top-down fashion, in which case inhibitory stimulation would be preferable. A key study illustrated these opposite mechanisms in emotion regulation in healthy controls vs. MDD patients (Johnstone et al., 2007): during emotional reappraisal, limbic frontal regions suppressed amygdala activity in controls, but counterproductively increased amygdala activity in MDD.

For NIBS interventions, direct suppression of the amygdala is challenging due to its deep location; strategies aimed at damping negative valence systems will therefore likely target in prefrontal cortex and insula. Excitatory prefrontal NIBS has been recently shown to attenuate amygdala-dependent negative processing in healthy controls (Baeken et al., 2010; Guhn et al., 2014), and this strategy may be best in "bottom-up" pathology, where emotional reappraisal/self-regulation systems are underactive rather than pathologically hyperactive (i.e., in BN and BED). Conversely, where negative valence systems are driven by "topdown" pathology, and self-regulation is if anything excessive, inhibitory stimulation may be preferable. Inhibitory NIBS of the DMPFC and lateral OFC both show promise in obsessivecompulsive disorder (Mantovani et al., 2010; Nauczyciel and Drapier, 2012; Dunlop K. et al., 2015), and these strategies may be better suited to AN-R, particularly in cases with comorbid OCD.

\section{Positive Valence Systems}

Positive valence systems encompass neural circuits related to motivation, reward seeking, and habit formation behaviors. According to a recent meta-analysis in healthy controls, positive stimuli are associated with activity in the VMPFC and ACC (Lindquist et al., 2015). All three major EDs, AN, BN, and BED, have been previously shown to be altered in this dimension (Figure 1).

From a behavioral perspective, AN patients show diminished sensitivity to conventional reward, as evident on psychometric measures (Harrison et al., 2010; Glashouwer et al., 2014) and delay discounting tasks (Steinglass et al., 2012). From a neurobiological perspective, ANR patients likewise display a blunted neural response to food reward in the insula and striatum (Wagner et al., 2008), decreased response to food images in the insula (Holsen et al., 2012; Oberndorfer et al., 2013b), and altered striatal activation during a reward-learning paradigm (Wagner et al., 2007). In a recent fMRI study of delay discounting in AN patients and healthy controls, AN patients had a marked preference for delayed rewards, associated with lower activation in the striatum and dorsal ACC during decision-making; these behavioral and neural abnormalities normalized to control levels after treatment (Decker et al., 2014). However, another study found that weight restoration did not affect choice behavior on a delay discounting task (Ritschel et al., 2015), suggesting that a preference for delayed over immediate rewards may be an endophenotypic feature in low-BMI individuals. In either case, the identified striatal and prefrontal regions are all involved in the motivational aspect of reward and food-reward processing.

There is also evidence that reward evaluation is altered in AN, in which secondary (contextual) rewards such as exercise and dietary restriction carry higher reward value relative to food or other primary rewards (Schebendach et al., 2007; Klein et al., 2010). The so-called "reward contamination theory" of AN posits a pathological re-configuration of the patient's reward system through stress-induced activation of the mesolimbic dopamine system, via ventral tegmental area opioid receptors. In this framework, AN behaviors essentially represent a maladaptive, but well-entrenched type of habit-formation (Keating et al., 2012; Walsh, 2013).

The findings that support this theory suggest that there is altered motivational salience for disease-related stimuli. For example, AN patients tend to rate physical exercise as "pleasant," more so than food (Giel et al., 2013). In fact, food-reward in $\mathrm{AN}$ activates a weight-gain fear response (i.e., negative valence systems) in the amygdala and extrastriate body rather than positive valence systems from the striatum, orbitofrontal cortex, 
and ACC (Vocks et al., 2011). The DLPFC is also hyperactive in response to images of food and the anticipation of reward, suggesting the presence of enhanced cognitive control over food cues and reward (Ehrlich et al., 2015; Sanders et al., 2015). ANR patients also have a high prevalence of comorbid OCD (Torresan et al., 2013). The level of compulsivity predicts the reactivity of the superior frontal gyrus, ACC and striatum and deactivation of the PFC to images of high-calorie foods (Rothemund et al., 2011), and lowered right DLPFC activity is seen in response to obsessive-compulsive symptom provocation in AN (Suda et al., 2014). Thus, hypofunctioning of primary reward systems (and potentially, hyperfunctioning of secondary/contextual reward systems) may be important target processes in ANR.

In contrast disorders in the $\mathrm{BN} / \mathrm{BED}$ spectrum are often associated with elevated primary reward valuation and reward sensitivity. These are typically associated with a higher willingness to work for a food reward (Schebendach et al., 2013), as well as higher impulsivity (Manwaring et al., 2011; Chan et al., 2013; Mole et al., 2015) At the neural level, BN and BED patients show increased activity for reward receipt in areas including the medial OFC, ventral striatum and insula (Schienle et al., 2009; Frank et al., 2011, 2012a; Radeloff et al., 2012; Weygandt et al., 2012; Oberndorfer et al., 2013a). BED patients display hyperactivations in the ventral striatum and inferior frontal gyrus during reward anticipation, and reduced medial PFC activity during a monetary incentive delay task (Balodis et al., 2014, 2013a). On PET imaging, areas like the insula, PFC and ventral striatum, associated with reward-motivation and food-reward processing, have altered serotonergic and dopaminergic binding in BN (Broft et al., 2012; Galusca et al., 2014). An important associated feature may also be deficient behavioral self-regulation and impulsivity. $\mathrm{BN}$ patients also show reduced activation in anticipation of a food reward is seen in ACC and right anterior insula; lower ACC activity predicts how much the patient will overeat (Frank et al., 2006; Bohon and Stice, 2011). Parallels have been drawn between the neural substrates of BN/BED and addiction, due to the similar alterations to motivation and reward-related circuitry on fMRI and task-based paradigms between the two psychopathologies (Filbey et al., 2012).

\section{Summary of Potential Positive Valence Targets}

In terms of positive valence systems, it appears that both restrictive and binging phenotypes of ED display alterations in incentive salience that is potentially modulated by the opioid system (Keating et al., 2012; Giuliano and Cottone, 2015; Figure 3). In the case of ANR, conventional primary rewards appear to be devalued in favor of pathological secondary or contextual rewards, such as starvation and excessive exercise. A broader preference for long-term/contextual over immediate primary rewards is also apparent in choice behavior during delay discounting. Neurally, the primary reward systems of the ventral striatum and ventromedial prefrontal cortex appear hypoactive, while contextual or secondary reward systems operating through lateral orbitofrontal and lateral temporal regions appear hyperactive. Hyperactivity in lateral orbitofrontal pathways is also strongly associated with OCD, and with compulsivity in general (Ahmari et al., 2013; Beucke et al., 2013). This finding would be consistent with the broader phenotype of ANR. Neurally-based strategies in ANR might therefore include enhancing primary reward value via medial prefrontal-striatal pathways, or attenuating secondary reward value via lateral prefrontal-striatal pathways. For instances where conventional rewards are less valued than maladaptive ones (restrictive, fat-phobic ED), inhibitory NIBS over lateral networks for maladaptive secondary rewards, and excitatory NIBS over medial networks for conventional rewards, may be a possible therapeutic protocol to realign incentive-salience mechanisms to normal, adaptive functioning.

In the case of binge/purge-related EDs, repeated exposures to the transient reward value of food intake (or the transient antianxiety effect of purging) would cause these behaviors to acquire pathologically high incentive value (especially in the presence of negative urgency), via neural mechanisms that parallel those of addiction. Effective strategies would therefore parallel those for substance addiction: enhancing cognitive/impulse control over urges to binge and purge, or suppressing urge intensity.

NIBS strategies for enhancing cognitive control involve excitatory stimulation of the nodes of the salience network, including the DLPFC, dACC, and insula (Dunlop et al., accepted). Each of these targets have demonstrated efficacy in substance dependence (Mishra et al., 2010; De Ridder et al., 2011; Meng et al., 2014), with effects apparently mediated by enhanced control rather than reduced urge. Recently, excitatory rTMS over the dACC has been reported to reduce symptoms in treatmentresistant binge/purge $\mathrm{ED}$, via enhanced integrity of frontostriatal circuits in the salience network (Dunlop J. et al., 2015).

NIBS may also be capable of suppressing urge, by targeting frontopolar and ventromedial sites. In one preclinical rTMS study, substance use disorder patients underwent inhibitory rTMS over the ventral frontal pole during a task evoked a cue-related craving response. A single session of inhibitory rTMS reduced the severity of craving in this group relative to sham, and stimulation proved capable of engaging core reward nodes in the ventral striatum, as well as the associated ventromedial prefrontal regions (Hanlon et al., 2013, 2015). Urge suppression via inhibitory ventromedial prefrontal stimulation has yet to be attempted in $\mathrm{ED}$, but would be a reasonable strategy to complement excitatory salience-network stimulation in binge/purge-related ED populations.

\section{Cognitive Systems}

The cognitive systems dimension refers to processes responsible for cognitive processing, including attention, perception, memory, language, and cognitive control. In healthy control studies, these behaviors are associated with activity in the DMPFC, DLPFC, and anterior insula (Albares et al., 2014; Cho et al., 2014; Luo et al., 2014; Reineberg et al., 2015). These networks tend to be associated with the central executive and salience resting-state networks (Reineberg et al., 2015), responsible for response selection and inhibition.

Abnormal cognitive control mechanisms are evident in most ED populations (Figure 1). On the one hand, BN and BEDtype diagnoses tend to display reduced capacity for impulse and 


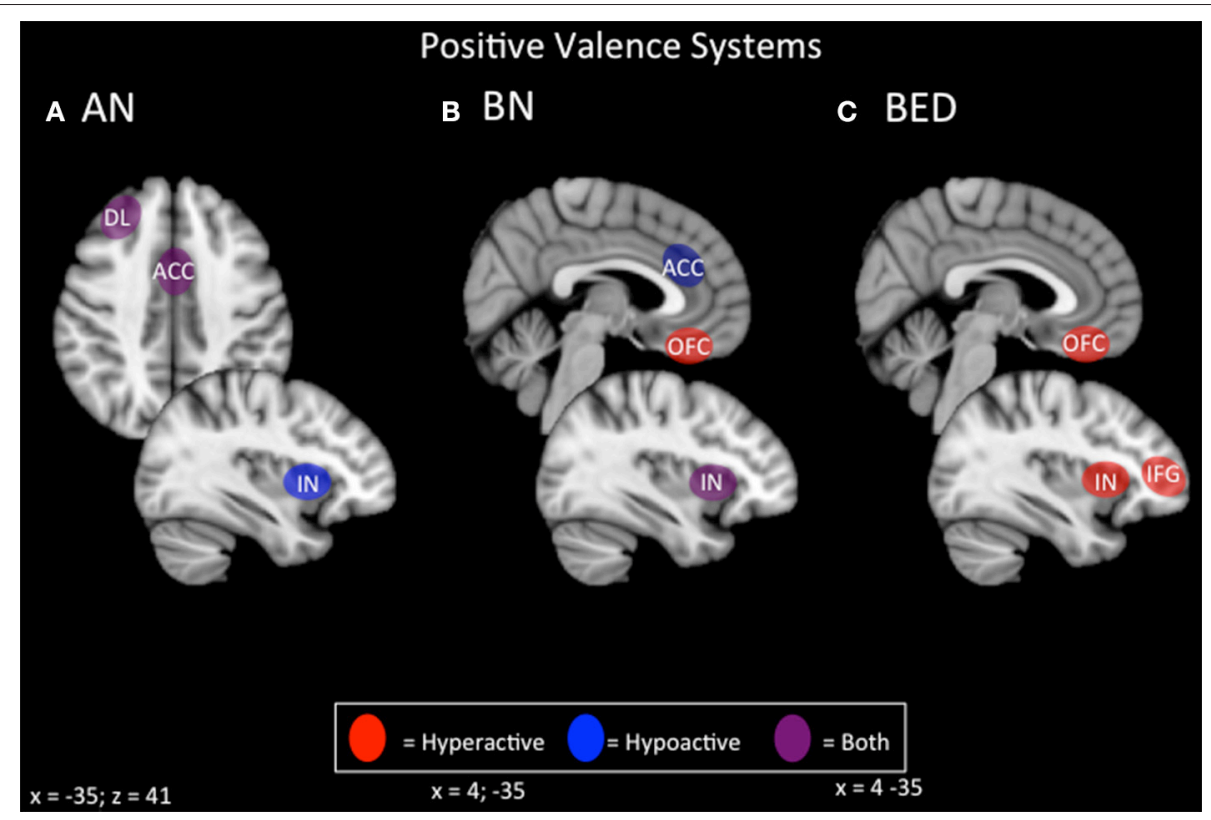

FIGURE 3 | Candidate NIBS targets that address abnormal phenotypes related to the RDoC positive valence dimension. (A) Candidate positive valence NIBS targets for anorexia nervosa (AN) (Wagner et al., 2007, 2008; Rothemund et al., 2011; Vocks et al., 2011; Holsen et al., 2012; Oberndorfer et al., 2013b; Torresan et al., 2013; Decker et al., 2014; Suda et al., 2014; Ehrlich et al., 2015; Sanders et al., 2015). The dorsolateral prefrontal cortex (DL) is both hyperactive when the participant views images of food, but hypoactive during symptom, particularly OCD-related, provocation. The anterior cingulate cortex (ACC) is also differentially activated; it is hyperactive when the participant views images of food, but hypoactive when the participant delays a reward. Also, the insula (IN) is hypoactive when the participant views images of food. (B) Candidate positive valence NIBS targets for bulimia nervosa (BN) (Frank et al., 2006, 2011; Bohon and Stice, 2011; Broft et al., 2012; Radeloff et al., 2012; Weygandt et al., 2012; Oberndorfer et al., 2013a; Galusca et al., 2014). The ACC is hypoactive during reward anticipation, and this hypoactivity predicts later overeating. The orbitofrontal cortex (OFC) is hyperactive during the receipt of a reward. The IN is both hyperactive during the receipt of a reward, but hypoactive during reward anticipation. (C) Candidate positive valence NIBS targets for binge eating disorder (BED) (Schienle et al., 2009; Frank et al., 2012a; Weygandt et al., 2012; Balodis et al., 2013a, 2014). Both the OFC and the IN are abnormally hyperactive during the receipt of a reward, while the inferior frontal gyrus (IFG) is hyperactive during reward anticipation.

cognitive control. This is particularly evident for disease-relevant stimuli (Wu et al., 2013), but is also apparent for positive and negative emotional valence images (Tapajóz P de Sampaio et al., 2015), suggesting a broader endophenotype of deficient cognitive and behavioral control. In fact, binge episodes are partially defined by the individual's loss of control during eating, and impulse control disorders (ICD) are common comorbidities (Fernández-Aranda et al., 2008). Purging behaviors are also associated with higher levels of impulsivity, and different forms of purging may represent separate manifestations of compulsivity and impulsivity (Hoffman et al., 2012).

On the other hand, restrictive-type EDs tend to show a different profile of cognitive control abnormalities. Cognitive control capacity may appear above normal levels in certain domains, such as temporal discounting (Steinglass et al., 2012). However, cognitive control may be abnormal in certain specific domains related to the illness; for example, for negative valence images (Tapajóz P de Sampaio et al., 2015), food stimuli (Oberndorfer et al., 2013b; Sanders et al., 2015), or body-imagerelated stimuli (Lee et al., 2014). AN patients also have altered cognitive control depending on the reward valence of the object, as the impulse control networks are overly activated for physical exercise relative to food images in a go/no-go task (Kullmann et al., 2014). AN patients also show a reduced ability to switch to an optimal decision-making strategy, called cognitive flexibility (Zastrow et al., 2009).

From a neural perspective, impulsive-type deficits on response control tasks are related to lower frontostriatal activations. BED patients show reduced activity in the inferior frontal gyrus, ventromedial PFC and insula during the Stroop task, and this diminished activity is associated with poor dietary restraint (Balodis et al., 2013b). BED prefrontal hypoactivity has also been correlated with psychometric measures of attentional impulsiveness and a disease-relevant go/no-go task (Hege et al., 2014). BN patients show hypoactivity in frontostriatal circuitry during cognitive control tasks like the Simon Spatial Incompatibility task; affected areas include the inferior frontal gyrus, striatum, ACC, OFC, DLPFC, and middle frontal gyrus (Marsh et al., 2009, 2011; Celone et al., 2011). On the go/no-go task, adolescent BN and ANBP patients display hyperactivations in the ACC and right DLPFC, albeit without impaired task performance relative to controls (Lock et al., 2011).

AN patients also show hypoactivity in frontostriatal circuits from the medial PFC on a response inhibition task related to cognitive control deficits (Oberndorfer et al., 2011; Wierenga et al., 2014), but hyperconnectivity to a response inhibition task that used exercise-related stimuli as its cue (Kullmann et al., 2014). Additionally, AN patients also display poorer performance 
on cognitive flexibility tasks, and this performance is reflected by lower activity in frontostriatal circuits through the thalamus, ventral striatum, ACC, middle frontal gyrus, and ventrolateral PFC (Zastrow et al., 2009; Sato et al., 2013; Garrett et al., 2014; Wildes et al., 2014; Lao-Kaim et al., 2015). On resting-state fMRI, higher thalamo-cortical functional connectivity through the DLPFC and anterior PFC is associated with poorer performance on the Stroop task and working memory (Biezonski et al., 2015). Thus, domain-specific abnormalities of cognitive control are evident at both the behavioral and the neural level in AN.

\section{Summary of Potential Cognitive Control Targets}

Both restricting- and binge/purge-type EDs show deficits on tasks related to cognitive control, including behavioral inhibition, working memory, selective attention, and cognitive flexibility (Figures 1, 4). Generally, BED displays poorer response inhibition and lower activity in the inferior frontal gyrus and ventromedial $\mathrm{PFC}$, both of which are accessible via excitatory forms of NIBS. BN and ANBP display lower activity in the inferior frontal gyrus, ACC, OFC, and DLPFC; all but the OFC are easily accessible for excitatory NIBS. As noted earlier, excitatory NIBS of salience-network nodes in DLPFC, DMPFC, and anterior insula appears to improve cognitive control and impulsivity even in healthy controls (Cho et al., 2014, 2010; Meng et al., 2014). Enhanced cognitive control, via improved frontostriatal connectivity through these salience-network nodes, may mediate recently reported improvements in binge and purge behaviors with excitatory DMPFC-rTMS (Dunlop J. et al., 2015). Similar effects via similar mechanisms should be expected for excitatory rTMS targeting DLPFC and anterior insula.

For AN, neural correlates of cognitive control show considerable variability depending on the task and valence of stimuli. On the one hand, AN patients in some studies show broad deficits of cognitive control and flexibility, and hypoactivity of the frontostriatal circuitry, during many tasks related to cognitive control; hence, excitatory NIBS might be beneficial if combined with cognitive tasks during stimulation. On the other hand, patients sometimes show the reverse pattern of hyperconnectivity and excessive cognitive control/compulsivity in these same circuits, within illnessspecific domains; excitatory stimulation may therefore be unhelpful, or could potentially exacerbate illness. In keeping with this concern, high-frequency DMPFC-rTMS was recently reported to exert a paradoxical inhibitory effect on frontostriatal connectivity in a subpopulation of ED patients with high baseline connectivity; these patients showed symptomatic worsening rather than improvement (Dunlop J. et al., 2015). Thus, targeting cognitive control in AN-R may require a more nuanced approach than is the case for binge-purge symptoms.

\section{Social Processing Systems}

Social processing systems refer to circuits involved in social communication, and the perception and understanding of oneself and others. Targets identified in healthy controls include the insula, responsible for interoception (Craig, 2002); the temporoparietral junction, for theory of mind-related processing (Saxe and Kanwisher, 2003); and higher-order visual processing regions, for processing one's own and others' faces (Hummel et al., 2013).

This dimension has received less attention in the ED literature relative to positive/negative valence systems and cognitive control (Figure 1). However, it may have relevance in $\mathrm{AN}$ patients, who show higher levels of alexithymia, deficits in visceral sensory perception or "interoception" (Craig, 2002; Strigo et al., 2013), and distorted perceptions of body shapes (Suchan et al., 2013). AN patients with higher levels of alexithymia show lower ACC, PCC, and right temporoparietal junction (TPJ) activation during social decision-making tasks (Miyake et al., 2009, 2012; McAdams and Krawczyk, 2011). More specifically, ANR patients display altered anterior and dorsal mid-insula activations based on the modality of interoception they are attending to (Kerr et al., 2015). On resting-state fMRI, AN patients also display increased functional connectivity from the anterior insula to the default mode network associated with self-reported problems with interoceptive awareness, suggesting a heightened level of cognitive control toward interoceptive processes (Boehm et al., 2014). AN patients also have altered neural responses to visually-presented body shapes, particularly in areas associated with visual processing and reward: the ventral striatum, extrastriate body area (EBA), DLPFC, parietal regions, medial PFC, and fusiform gyrus (Cowdrey et al., 2012; Spangler and Allen, 2012; Castellini et al., 2013; Fladung et al., 2013; Suchan et al., 2013; Suda et al., 2013; Fonville et al., 2014). Finally, two recent studies have also identified areas of abnormal activation in response to benevolent and malevolent social relationships. During benevolent social relations, AN patients tend to display reductions in DMPFC, possibility related to lowered reward valence for social reward and interaction (McAdams et al., 2015; Via et al., 2015).

In summary, AN patients may show deficits across multiple domains related to self-perception (alexithymia, interoception, and body shape perception) and social function (interpersonal interaction, theory of mind; Figures 1, 5). The latter function has been successfully enhanced with excitatory DMPFC-rTMS in autism-spectrum disorder (Enticott et al., 2011, 2014). During social interactions, AN patients likewise tend to display DMPFC hypoactivity during social interaction, and so excitatory stimulation over this region may worth exploring. For selfperception, relevant targets include anterior insula (alexithymia), posterior insula (interoception), TPJ and EBA (social cue perception, body shape perception). NIBS has successfully targeted each of these regions in other applications (Ciampi de Andrade et al., 2012; Dinur-Klein et al., 2014; Donaldson et al., 2015). Excitatory stimulation of the insula and TPJ may be worth exploring for alexithymia and deficits in interoception. Conversely, inhibitory stimulation of the TPJ and EBA may be worth exploring for aberrant self- and body perception.

\section{NIBS TECHNIQUES AS THERAPEUTIC INTERVENTIONS IN ED}

For the following section, a systematic review was completed using PubMed (NIH, http://www.ncbi.nlm.nih.gov/pubmed), 


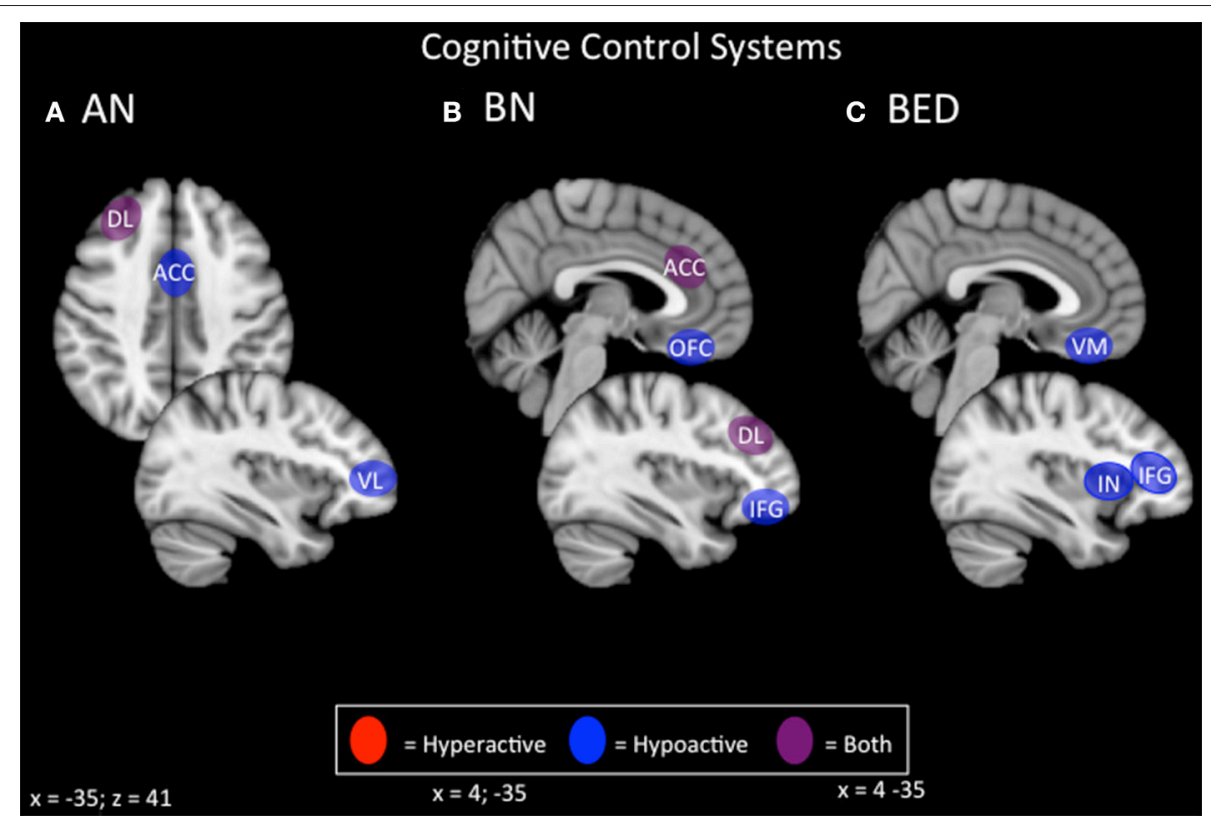

FIGURE 4 | Candidate NIBS targets that address abnormal phenotypes related to the RDoC cognitive control dimension. (A) Candidate cognitive control NIBS targets for anorexia nervosa (AN) (Oberndorfer et al., 2011; Sato et al., 2013; Garrett et al., 2014; Wierenga et al., 2014; Wildes et al., 2014; Biezonski et al., 2015; Lao-Kaim et al., 2015). The dorsolateral prefrontal cortex (DL) is both hyperactive during interference control tasks (such as the Stroop task), and for working memory, but hypoactive during cognitive flexibility and set-shifting tasks. The anterior cingulate cortex (ACC) is hypoactive during response inhibition tasks, while the ventrolateral prefrontal cortex (VL) is hypoactive during cognitive flexibility tasks. (B) Candidate cognitive control NIBS targets for bulimia nervosa (BN) (Marsh et al., 2009; Rossi and Hallett, 2009; Celone et al., 2011; Lock et al., 2011). Both the ACC and the DL are hyperactive during response inhibition tasks, but hypoactive during interference control tasks, while both the orbitofrontal cortex (OFC) and inferior frontal gyrus (IFG) are hypoactive during inference control tasks. (C) Candidate cognitive control NIBS targets for binge eating disorder (BED) (Balodis et al., 2013b; Hege et al., 2014). The ventromedial prefrontal cortex (VM), insula (IN), and IFG are abnormally hypoactive during interference control, poor dietary restraint, impulsivity, and response inhibition.

with searches containing the following terms: first, clinical terms for the three ED diagnoses in this review and related phenotypes (BN, AN, BED, binging, purging, excessive exercise), and second, NIBS related terms (rTMS, TMS, tDCS).

\section{NIBS Overview: rTMS and tDCS}

rTMS applies powerful, focused magnetic field pulses over the scalp to elicit action potentials in the underlying region of cortex. Typically, treatment sessions occur once daily, for a total of 2030 daily sessions (Carpenter et al., 2012; Solvason et al., 2014). rTMS mechanisms are thought to involve synaptic plasticity via long-term potentiation or depression, with the direction of effect dependent on the stimulation intensity, duration, and pattern (Pascual-Leone et al., 1998; Maeda et al., 2000). Higher frequency stimulation $(5-20 \mathrm{~Hz})$ is usually considered to be excitatory, while low frequency $(<1 \mathrm{~Hz})$ stimulation is considered inhibitory (Pascual-Leone et al., 1994; Chen et al., 1997). More recently, however, considerable heterogeneity on electrophysiological, neuroimaging, and clinical measures has been found for most if not all patterns of rTMS (Maeda et al., 2000; Eldaief et al., 2011; Dunlop J. et al., 2015; Dunlop K. et al., 2015; Nettekoven et al., 2015).

tDCS, on the other hand, uses a constant, low amplitude current to modulate cortical excitability, rather than eliciting action potentials directly. As with rTMS, sessions typically occur daily, for a total of 10-30 sessions (Meron et al., 2015). While the mechanisms of tDCS are still debated, it is likely that modulated cortical excitability also elicits subtle effects on synaptic plasticity via long-term potentiation and depression (Brunoni et al., 2012). Anodal stimulation is considered excitatory, and cathodal stimulation inhibitory. However, as with rTMS, both types of tDCS display considerable inter-individual variability in their effects (Wiethoff et al., 2014). Newer variants such as transcranial alternating current stimulation (tACS), may exert more consistent, frequency-specific effects (Voss et al., 2014); however, their therapeutic potential is poorly understood at present.

\section{NIBS as a Treatment for BED and Food Craving}

To date, the majority of published NIBS-ED studies have focused on female patients with abnormally high food craving or urge to eat, as opposed to a specific formal DSM-5 diagnosis (Tables 2, 3; McClelland et al., 2013; Grall-Bronnec and Sauvaget, 2014; ValLaillet et al., 2015). These preclinical studies typically involve a single session of stimulation, with subjectively rated cueinduced craving as the primary outcome. With rTMS, two studies reported contradictory results for $10 \mathrm{~Hz}$ stimulation of the left DLPFC rTMS: one study $(n=28)$ found decreased craving after active vs. sham stimulation (Uher et al., 2005), while the other 


\section{Social Processing}

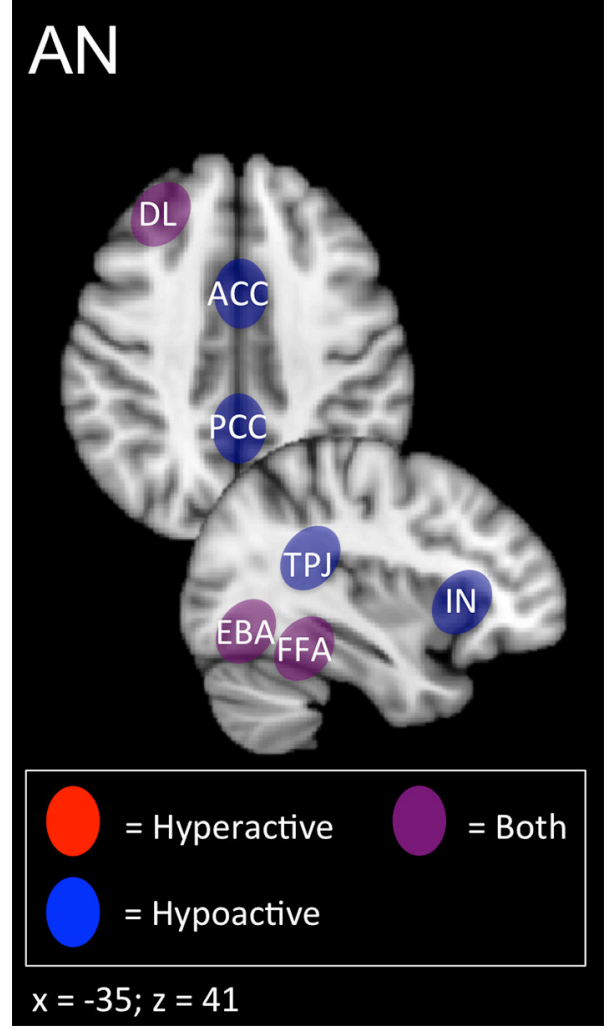

FIGURE 5 | Candidate NIBS targets that address abnormal phenotypes related to the RDoC social processing dimension in anorexia nervosa (AN) (Cowdrey et al., 2012; Miyake et al., 2012; Spangler and Allen, 2012; Castellini et al., 2013; Fladung et al., 2013; Suda et al., 2013; Boehm et al., 2014; Fonville et al., 2014; Kerr et al., 2015; McAdams et al., 2015; Via et al., 2015). The anterior cingulate cortex (ACC), posterior cingulate cortex (PCC), and temporoparietal junction (TPJ) are abnormally hypoactive during deficits in social decision-making and alexithymia, while low insula (IN) activity is related to deficits in interoceptive awareness. The dorsolateral prefrontal cortex (DL) is both abnormally hyperactive when the participant views oversized images of themselves, but hypoactive when viewing images depicting body-checking behavior. The fusiform face area (FFA) is both abnormally hyperactive when the participant views highly emotional facial expressions, but hypoactive when viewing distorted body shapes and images depicting body-checking behavior. The extrastriate body area (EBA) is both abnormally hyperactive when the participant views images of their own body, but hypoactive when those images are distorted.

$(n=10)$ found that active stimulation was no better than sham in terms of cue-induced craving control (Barth et al., 2011). The studies differed in stimulation parameters, however, and enrolled only healthy participants who self-reported having strong food cravings, but did not carry a formal ED diagnosis. Hence, it may be difficult to extrapolate these findings to the effects of a full therapeutic course of 20-30 sessions in patients with pathological deficits of self-control and a formal ED diagnosis.

There is also a growing body of literature investigating DLPFC-tDCS as a method to reduce craving and food intake. In four published studies recruiting individuals with strong food cravings, a single session of anodal right DLPFC/cathodal left DLPFC tDCS was able to reduce cue-induced craving, reduce food intake, and improve the participants' ability to resist food relative to sham-tDCS (Fregni et al., 2008; Goldman et al., 2011; Kekic et al., 2014; Lapenta et al., 2014). Future work involving tDCS should employ multiple sessions as opposed to a single session in a randomized, sham-controlled setting, as a treatment for the inappropriate eating patterns associated with BED. Studies in populations carrying a formal ED diagnosis, with significant functional impairment and distress, are also needed.

\section{NIBS as a Treatment for BN}

The earliest publication of rTMS as a potential treatment for BN is a case report of a patient diagnosed with comorbid depression and $\mathrm{BN}$ who achieved an unexpected remission of binge and purge symptoms and depressive improvements after 10 sessions of $20 \mathrm{~Hz}$ rTMS over the left DLPFC (Hausmann et al., 2004; McClelland et al., 2013; Table 2). Follow-up studies involving high frequency left DLPFC rTMS have been mixed: one group found that a single session reduced the urge to eat, the number of binges $24 \mathrm{~h}$ post-rTMS, and salivary cortisol levels (Van den Eynde et al., 2010; Claudino et al., 2011), while another study found no difference between active- and sham-rTMS after 15 sessions of $20 \mathrm{~Hz}$ rTMS over the left DLPFC (Walpoth et al., 2008). A more recent study applied a single session of excitatory left DLPFC-rTMS in 8 female patients with $\mathrm{BN}$, and reported reduced subjective ratings of craving post-rTMS, along with lower cerebral oxygenation in the DLPFC on near-infrared spectroscopy (Sutoh et al., 2016). These findings hint at the potential promise of DLPFC-rTMS for BN, which would be in keeping with the much more extensive literature demonstrating that this intervention enhances cognitive control in healthy subjects (Cho et al., 2010), and patient populations (Van den Eynde et al., 2010), with therapeutic effects in mechanistically related disorders such as addiction (Gorelick et al., 2014).

More recently, our group has shifted the rTMS stimulation target from the DLPFC to the DMPFC, as a potential treatment for major depression (Downar et al., 2014; Salomons et al., 2014; Bakker et al., 2015). As with first case report of DLPFC-rTMS for $\mathrm{BN}$, we too found an unexpected remission of chronic treatment refractory binge and purge symptoms in an MDD patient with comorbid BN, following 20 sessions of $10 \mathrm{~Hz}$ DMPFC-rTMS. The onset of effect was rapid, occurring in the first week of treatment, and was maintained for 9 weeks post-treatment (Downar et al., 2012). In a follow-up, open-label series of $10 \mathrm{~Hz}$ DMPFC-rTMS in $28 \mathrm{ED}$ patients with binge/purge behaviors, we noted $\geq 50 \%$ symptom reduction in $57 \%$. On resting-state fMRI, we found increased resting-state functional connectivity in fronto-striatal salience network circuits (through DMPFC, anterior insula, and ventral striatum) specifically in the treatment responders but not non-responders (Dunlop J. et al., 2015), consistent with similar findings for DMPFC-rTMS in MDD and obsessive-compulsive disorder (Salomons et al., 2014; Dunlop K. et al., 2015). These findings suggest that DMPFC-rTMS may improve bulimic symptoms through an improvement of topdown cognitive control over urges, via frontostriatal circuits through salience-network nodes. Future work should include a 


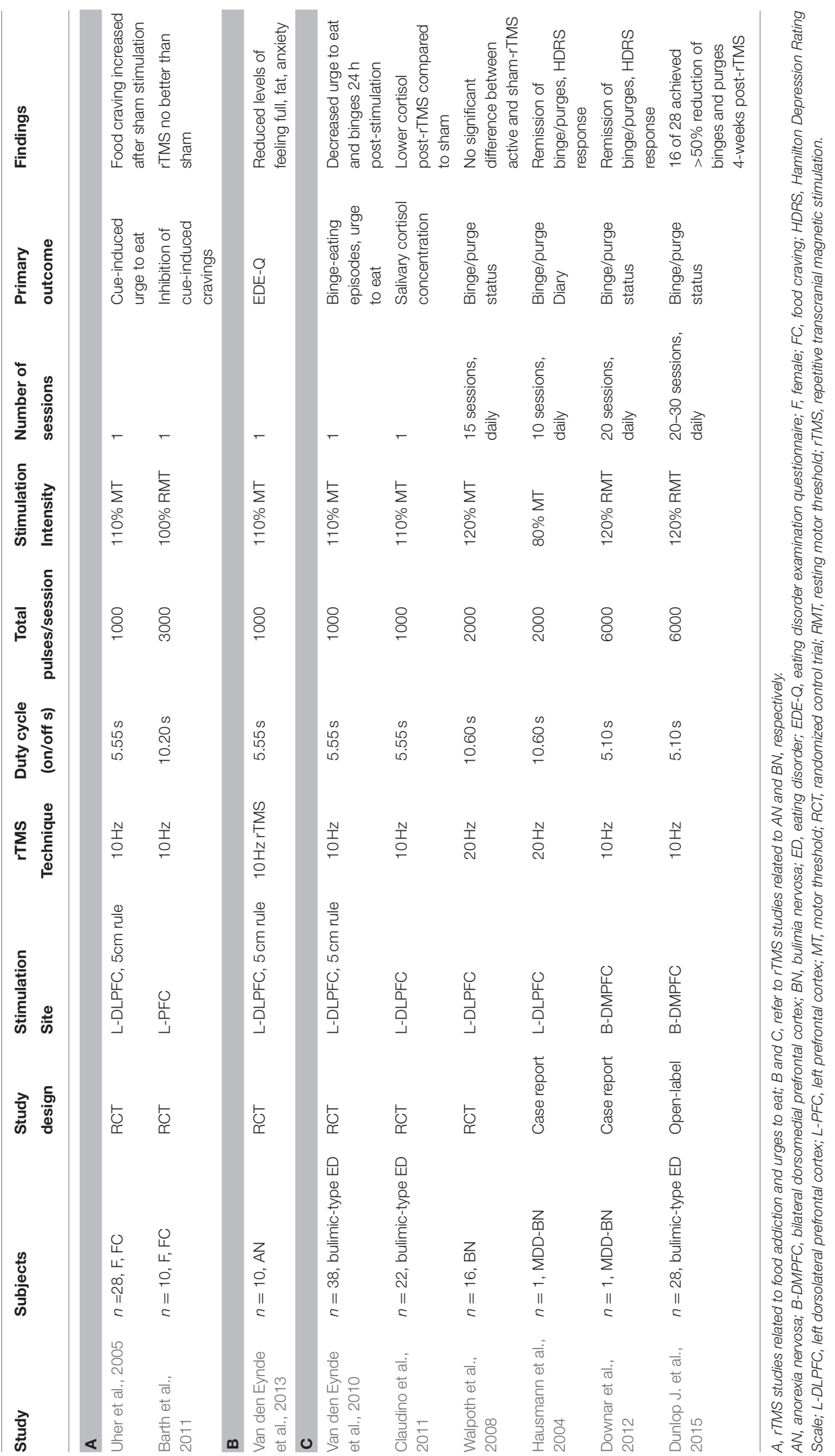


TABLE 3 | Overview of the available ED-tDCS literature.

\begin{tabular}{|c|c|c|c|c|c|c|c|c|}
\hline Study & Subjects & $\begin{array}{l}\text { Study } \\
\text { Design }\end{array}$ & $\begin{array}{l}\text { Anodal } \\
\text { Site }\end{array}$ & $\begin{array}{l}\text { Cathodal } \\
\text { Site }\end{array}$ & $\begin{array}{l}\text { Stimulation } \\
\text { Intensity }\end{array}$ & $\begin{array}{l}\text { Number of } \\
\text { sessions }\end{array}$ & $\begin{array}{l}\text { Primary } \\
\text { Outcome }\end{array}$ & Findings \\
\hline \multicolumn{9}{|l|}{ A } \\
\hline $\begin{array}{l}\text { Fregni et al., } \\
2008\end{array}$ & $\begin{array}{l}n=23, \mathrm{HC} \text { with } \\
\text { urges to eat }\end{array}$ & $\begin{array}{l}\text { Sham-controlled, } \\
\text { crossover }\end{array}$ & R-DLPFC & L-DLPFC & $2 \mathrm{~mA}, 20 \mathrm{~min}$ & 1 & $\begin{array}{l}\text { Craving VAS, food } \\
\text { consumption }\end{array}$ & $\begin{array}{l}\text { Reduced craving in } \\
\text { active tDCS, less } \\
\text { consumption }\end{array}$ \\
\hline $\begin{array}{l}\text { Goldman } \\
\text { et al., } 2011\end{array}$ & $\begin{array}{l}\mathrm{n}=19, \mathrm{HC} \text { with } \\
\text { urges to eat }\end{array}$ & $\begin{array}{l}\text { Sham-controlled, } \\
\text { crossover }\end{array}$ & R-DLPFC & L-DLPFC & $2 \mathrm{~mA}, 20 \mathrm{~min}$ & 1 & $\begin{array}{l}\text { Craving VAS, Resist } \\
\text { food }\end{array}$ & $\begin{array}{l}\text { Reduced craving, } \\
\text { increased ability to } \\
\text { resist food }\end{array}$ \\
\hline $\begin{array}{l}\text { Kekic et al., } \\
2014\end{array}$ & $\begin{array}{l}n=20, \mathrm{HC} \text { with } \\
\text { urges to eat }\end{array}$ & $\begin{array}{l}\text { Sham-controlled, } \\
\text { crossover }\end{array}$ & R-DLPFC & L-DLPFC & $2 \mathrm{~mA}, 20 \mathrm{~min}$ & 1 & Craving VAS & $\begin{array}{l}\text { Reduced craving for } \\
\text { sweet foods }\end{array}$ \\
\hline $\begin{array}{l}\text { Lapenta } \\
\text { et al., } 2014\end{array}$ & $\begin{array}{l}n=9, \mathrm{HC} \text { with } \\
\text { urges to eat }\end{array}$ & $\begin{array}{l}\text { Sham-controlled, } \\
\text { crossover }\end{array}$ & R-DLPFC & L-DLPFC & $2 \mathrm{~mA}, 20 \mathrm{~min}$ & 1 & $\begin{array}{l}\text { Cue-induced food } \\
\text { craving }\end{array}$ & Reduced food intake \\
\hline \multicolumn{9}{|l|}{ B } \\
\hline $\begin{array}{l}\text { Khedr et al., } \\
2014\end{array}$ & $n=7, \mathrm{AN}$ & Open-Label & L-DLPFC & $\mathrm{N} / \mathrm{A}$ & $2 \mathrm{~mA}, 25 \mathrm{~min}$ & 10, daily & EDI and EAT & $\begin{array}{l}\text { Significant effect of } \\
\text { time on EAT and EDI }\end{array}$ \\
\hline
\end{tabular}

$A$, tDCS studies related to food addiction and urges to eat; $B$, tDCS studies related to $A N$.

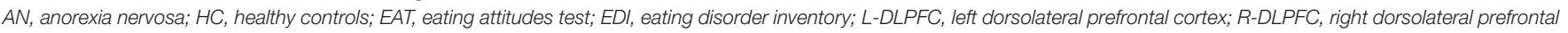
cortex; tDCS, transcranial direct current stimulation; VAS, visual analog scale.

sham-controlled arm, along with behavioral measures to better characterize the cognitive domains mediating the therapeutic effects of DMPFC-rTMS in BN.

\section{NIBS as a Treatment for AN}

To date, there are few published sham-controlled trials on tDCS and rTMS as treatments for AN (Bainbridge and Brown, 2014; McClelland et al., 2013). One preclinical study in a small sample of AN patients $(n=10)$ applied a single session of $10 \mathrm{~Hz}$ left DLPFC-rTMS, with patients reporting less anxiety and less feeling full and feeling fat (Table 2; Van den Eynde et al., 2013). An open-label case series in 5 AN patients applied 20 sessions of excitatory DLPFC-rTMS, reporting improvements in anxiety, feeling fat/full and urge to restrict/exercise over the course of treatment, enduring to 6 months; however, these effects had waned by 12-months post-treatment (McClelland et al., 2016). Another open-label series in $7 \mathrm{AN}$ patients applied 10 sessions of anodal left DLPFC tDCS (Table 3), reporting improvements on the Eating Disorders Inventory (EDI) and the Eating Attitude Test (EAT) (Khedr et al., 2014). Although, these early publications are promising, further preliminary work in larger groups, with a longer course and sham control, must be performed to determine whether rTMS and tDCS are efficacious treatments for AN.

\section{CONSIDERATIONS FOR FUTURE STUDIES}

\section{Patient Selection}

In an attempt to limit heterogeneity, inclusion criteria for NIBS studies in ED patients are often based on DSM5 diagnostic categories. However, as noted above, DSM5 diagnoses still encompass substantial heterogeneity, and may conflate neurobiologically distinct endophenotypes. Future studies enrolling ED patients for NIBS trials should make efforts to at least characterize the underlying phenotypes within the clinical populations they are treating, and ideally should target a specific endophenotype associated with a specific neural substrate. Such studies should also measure behavioral or biological markers of this endophenotype to assess whether the target process was successfully engaged, and whether the engaged process did indeed mediate any observed symptomatic improvements.

\section{Intervention Parameters}

Several treatment parameters are important to consider when designing NIBS studies in ED. First, treatment parameters (protocol, total number of sessions, and number of sessions per day) needs to be selected, keeping in mind both patient convenience and therapeutic efficacy. In the older MDD-NIBS literature, 20-30 sessions of once daily rTMS is the standard protocol, with sessions lasting up to $45-60 \mathrm{~min}$. However, such schedules are onerous for patients and limit overall clinic capacity. More recent studies have begun to explore much briefer protocols, such as 1-3 min theta-burst stimulation ( $\mathrm{Li}$ et al., 2014), which have been reported to achieve equivalent or superior outcomes (Bakker et al., 2015). Other protocols, such as quadripulse stimulation (QPS), have been reported to achieve much more consistent effects across individuals (Huang et al., 2005; Tsutsumi et al., 2014). Still other recent MDD trials have delivered multiple sessions per day (up to five sessions a day), to complete the full course in 4-10 days rather than the usual 46 weeks (Holtzheimer et al., 2010; Baeken et al., 2014). Future ED rTMS trials should make use of these innovations to reduce patient burden, increase capacity or consistency, and accelerate the pace of improvement.

\section{Concurrent Tasks or Therapies}

Another consideration for NIBS trials for ED is whether stimulation should be applied concurrently with psychotherapy or a specific cognitive/behavioral task, as opposed to simply 
during rest. This is especially the case if NIBS protocols are designed based on RDoC dimensions, and targets cortical regions based on abnormal activation on certain tasks. As discussed above, many areas, including the ACC/mPFC, DLPFC, insula, inferior frontal gyrus, and ventrolateral PFC are hyperactive to some tasks, but hypoactive in others. With stimulation during rest, it is difficult to assess or constrain the activation state of the underlying cortical target. Having the patient perform illness-specific cognitive task has now been shown to enhance (or reduce) the therapeutic effects of rTMS across several different indications. For example, reading trauma-related scripts during rTMS enhanced efficacy for PTSD (Isserles et al., 2013); undergoing rTMS in the presence of substance cues enhances efficacy in addiction (Dinur-Klein et al., 2014). Analogous approaches may be helpful in ED.

\section{Treatment Target}

A final consideration for ED-NIBS concerns the feasibility of the proposed target. Although, targets such as DLPFC, DMPFC, OFC, and TPJ have now been targeted in a variety of studies, others such as ventromedial prefrontal cortex or anterior insula may be difficult to reach without specially designed coils, and without also stimulating overlying structures. More feasibility studies are needed to assess how well that these areas can be engaged with rTMS and tDCS (Chib et al., 2013).

Another consideration during target selection is determining the appropriate stimulation intensity in the case of rTMS. For example, treatment intensity is determined by measuring the resting motor threshold of region of cortex directly posterior to stimulation site; in these cases, resting motor threshold is determined by the activation of the thumb or big toe for DLPFC and DMPFC, respectively (Schutter and van Honk, 2006; Hallett, 2007). It is therefore unclear for novel stimulatory sites what would be the most appropriate and reliable sites to determine optimal stimulation intensity. Studies using finite element modeling may also be helpful for optimizing stimulator placement and intensity (Nitsche et al., 2012).

The effects of rTMS also dramatically decrease the farther the site is from the scalp surface (Kozel et al., 2000), and so it is likely that stimulation intensity will have to be quite large for deep targets such as anterior insula or VMPFC. If this is the case, it is likely that pain tolerability will be a factor. In addition, trigeminal nerve pain, scalp pain, and headaches are common adverse effects associated with rTMS (Machii et al., 2006; Rossi and Hallett, 2009). Tolerability will need to be maintained when stimulating these novel targets, particularly in scalp regions with trigeminal innervation, such as the frontopolar, orbitofrontal, or temporopolar regions. This may be challenging for more intense rTMS protocols, although helmet-shaped "deep TMS" coil geometries may be somewhat helpful in allowing deep stimulation of these regions while maintaining tolerability (Roth et al., 2007). Certain targets (e.g., OFC, frontopolar cortex) may be more amenable to tDCS, which is relatively painless compared to rTMS. Another non-invasive technique worthy of future investigation is cutaneous non-invasive vagus nerve stimulation, which is also delivered via external electrodes. Its more invasive counterpart, surgically-implanted vagus nerve stimulation has recently shown some efficacy for medication-resistant depression (Ben-Menachem et al., 2015; Grimonprez et al., 2015).

Finally, stimulating multiple targets in a single session might be the optimal way to address all the abnormal behavioral dimensions in a given ED patient. Different ED symptom dimensions map to different cortical targets, and so confining stimulation to a single target may be insufficient to address multi-dimensional ED pathology. For example, in BN, excitatory stimulation of the DMPFC/insula combined with inhibitory stimulation of the VMPFC may be a more optimal strategy for enhancing cognitive control while reducing urge intensity. "Deep TMS" coils have been designed to stimulate multiple targets simultaneously (Dinur-Klein et al., 2014), and multichannel coils allow different protocols at different targets simultaneously (Roth et al., 2014). However, the therapeutic effects of sequential vs. simultaneous stimulation have not yet been compared directly. Further research should be done to describe the safety, tolerability, clinical efficacy, and neural mechanisms of stimulating multiple targets, either sequentially or simultaneously.

\section{CONCLUSION}

Neuroimaging, psychometric, and behavioral findings are converging upon a new approach to classifying psychiatric disorders, including EDs, in terms of endophenotypes or symptom dimensions. New proposed frameworks, such as the $\mathrm{RDoC}$, seek to describe EDs in terms of dysfunction in specific underlying brain functions such as cognitive control, positive and negative valence, and social/self-related cognition. These functions in turn are gradually being linked to specific neurobiological processes, described at multiple levels spanning clinical symptomatology, behavioral task performance, neuroimaging studies of macro-scale network function, and cellular, molecular, and genetic mechanisms. With the advent of anatomically focal NIBS interventions, a "neuroanatomical formulation" of ED pathology may become relevant not only for basic science, but for clinical care.

At present, neuroanatomical, endophenotypic, and RDoC formulations of $\mathrm{ED}$ pathology must be considered tentative and preliminary. However, from available literature, it does appear that some of the tremendous and dynamic heterogeneity of symptoms in the ED population can be understood parsimoniously in terms of dysfunction in a few key cognitive systems and their associated neural circuits. For example, in BN and BED, binge and purge behaviors may acquire pathologically strong incentive salience by mechanisms similar to addiction; impaired cognitive control in turn renders binge/purge urges hard to resist, particularly during negative affect. NIBS strategies designed for addiction (e.g., enhancing cognitive control via salience-network stimulation and damping urge intensity via ventromedial stimulation) may be helpful in this setting. In ANR, this strategy may be less helpful; instead, targeting pathologically overactive negative-valence systems may address the excessive valuation of secondary over primary rewards, and the underlying compulsivity. NIBS strategies developed for OCD (such as inhibitory stimulation of the OFC and 
DMPFC) may be more helpful in this setting. Ancillary NIBS strategies for AN may also target distortions of body image, alexithymia, and deficits of interoception via insular, TPJ, and EBA stimulation. However, it must be acknowledged that nearly all of these approaches are at present theoretically based, and lacking even in preclinical support. The field is urgently in need of future studies in clinical populations, with adequate sample sizes and sham controls, and using endophenotypic markers to validate or refute the proposed mechanisms of action for NIBS in EDs.

To conclude, patients with EDs stand to benefit tremendously from ongoing progress in three areas: symptom characterization, diagnostic formulation, and targeted intervention. Recent initiatives will allow us to make better sense of the heterogeneity of ED pathology, both across individuals and within individuals over time. As we improve our abilities to identify robust symptom clusters, link those clusters to neural substrates, and target those substrates with NIBS interventions, treatment outcomes will improve. These advances need not occur at the expense of existing and well-validated treatment strategies involving medications, psychotherapy, and behavior modification. Rather, they will likely work in a synergistic fashion to complement and facilitate our existing treatment strategies: enhancing the cognitive control that is a prerequisitive for

\section{REFERENCES}

Ahmari, S. E., Spellman, T., Douglass, N. L., Kheirbek, M. A., Simpson, H. B., Deisseroth, K., et al. (2013). Repeated cortico-striatal stimulation generates persistent OCD-like behavior. Science 340, 1234-1239. doi: $10.1126 /$ science. 1234733

Åhs, F., Kragel, P. A., Zielinski, D. J., Brady, R., and LaBar, K. S. (2015). Medial prefrontal pathways for the contextual regulation of extinguished fear in humans. Neuroimage 122, 262-271. doi: 10.1016/j.neuroimage.2015.07.051

Albares, M., Lio, G., Criaud, M., Anton, J.-L., Desmurget, M., and Boulinguez, P. (2014). The dorsal medial frontal cortex mediates automatic motor inhibition in uncertain contexts: evidence from combined fMRI and EEG studies. Hum. Brain Mapp. 35, 5517-5531. doi: 10.1002/hbm.22567

Amianto, F., Ottone, L., Abbate-Daga, G., and Fassino, S. (2015). Binge-eating disorder diagnosis and treatment: a recap in front of DSM-5. BMC Psychiatry 15:6. doi: 10.1186/s12888-015-0445-6

Arcelus, J., Mitchell, A. J., Wales, J., and Nielsen, S. (2011). Mortality rates in patients with anorexia nervosa and other eating disorders. A meta-analysis of 36 studies. Arch. Gen. Psychiatry 68, 724-731. doi: 10.1001/archgenpsychiatry.2011.74

Baeken, C., De Raedt, R., Van Schuerbeek, P., Vanderhasselt, M. A., De Mey, J., Bossuyt, A., et al. (2010). Right prefrontal HF-rTMS attenuates right amygdala processing of negatively valenced emotional stimuli in healthy females. Behav. Brain Res. 214, 450-455. doi: 10.1016/j.bbr.2010.06.029

Baeken, C., Marinazzo, D., Wu, G.-R., Van Schuerbeek, P., De Mey, J., Marchetti, I., et al. (2014). Accelerated HF-rTMS in treatment-resistant unipolar depression: Insights from subgenual anterior cingulate functional connectivity. World J. Biol. Psychiatry, 15, 286-297. doi: 10.3109/15622975.2013.872295

Bailer, U. F., Frank, G. K., Henry, S. E., Price, J. C., Meltzer, C. C., Mathis, C. A., et al. (2007). Exaggerated 5-HT1A but Normal 5-HT2A Receptor Activity in Individuals Ill with Anorexia Nervosa. Biol. Psychiatry 61, 1090-1099. doi: 10.1016/j.biopsych.2006.07.018

Bailer, U., Price, J., Meltzer, C. C., Mathis, C. A., Frank, G. K., Weissfeld, L., et al. (2004). Altered 5-HT(2A) receptor binding after recovery from bulimiatype anorexia nervosa: relationships to harm avoidance and drive for thinness. Neuropsychology 29, 1143-1155. doi: 10.1038/sj.npp.1300430 successful cognitive-behavioral treatments in $\mathrm{BN}$, or reducing the compulsivity and rigidity that hampers behavior modification in AN. Given the considerable patient burden and chronicity of EDs, these advances in treatment options will be a welcome change for patients, families and clinicians alike.

\section{AUTHOR CONTRIBUTIONS}

All authors listed, have made substantial, direct and intellectual contribution to the work, and approved it for publication.

\section{FUNDING}

JD has received research support from the Canadian Institutes of Health Research, the National Institutes of Health, the Klarman Family Foundation, the Edgestone Family Foundation, the Toronto General and Western Hospital Foundation, and in-kind support from MagVenture for investigator-initiated studies. BW has received research support from the Ontario Mental Health Foundation, the Price Foundation, The Klarman Foundation, the Canadian Institute for Health Research, and the National Institute for Mental Health. KD has received research support from the Canadian Institutes of Health Research, Vanier Canada Scholarship Program.

Bainbridge, K., and Brown, A. (2014). rTMS as a treatment for anorexia nervosa. Brain Stimul. 7, 149-150. doi: 10.1016/j.brs.2013.09.010

Bakker, N., Shahab, S., Giacobbe, P., Blumberger, D. M., Daskalakis, Z. J., Kennedy, S. H., et al. (2015). rTMS of the dorsomedial prefrontal cortex for major depression: safety, tolerability, effectiveness, and outcome predictors for $10 \mathrm{~Hz}$ versus intermittent theta-burst stimulation. Brain Stimul. 8, 205-215. doi: 10.1016/j.brs.2014.11.002

Balodis, I. M., Grilo, C. M., Kober, H., Worhunsky, P. D., White, M. A., Stevens, M. C., et al. (2014). A pilot study linking reduced fronto-Striatal recruitment during reward processing to persistent bingeing following treatment for bingeeating disorder. Int. J. Eat. Disord. 47, 376-384. doi: 10.1002/eat.22204

Balodis, I. M., Kober, H., Worhunsky, P. D., White, M. A., Stevens, M. C., Pearlson, G. D., et al. (2013a). Monetary reward processing in obese individuals with and without binge eating disorder. Biol. Psychiatry 73, 877-886. doi: 10.1016/j.biopsych.2013.01.014

Balodis, I. M., Molina, N. D., Kober, H., Worhunsky, P. D., White, M. A., Sinha, R., et al. (2013b). Divergent neural substrates of inhibitory control in binge eating disorder relative to other manifestations of obesity. Obesity 21, 367-377. doi: 10.1002/oby. 20068

Bär, K.-J., de la Cruz, F., Berger, S., Schultz, C. C., and Wagner, G. (2015). Structural and functional differences in the cingulate cortex relate to disease severity in anorexia nervosa. J. Psychiatry Neurosci. 40, 269-279. doi: 10.1503/jpn.140193

Bar, K.-J., de la Cruz, F., Berger, S., Schultz, C., and Wagner, G. (2015). Structural and functional differences in the cingulate cortex relate to disease severity in anorexia nervosa. J. Psychiatry Neurosci. 40, 269-279. doi: 10.1503/jpn.140193

Barth, K. S., Rydin-Gray, S., Kose, S., Borckardt, J. J., O’Neil, P. M., Shaw, D., et al. (2011). Food cravings and the effects of left prefrontal repetitive transcranial magnetic stimulation using an improved sham condition. Front. Psychiatry 2:9. doi: 10.3389/fpsyt.2011.00009

Ben-Menachem, E., Revesz, D., Simon, B. J., and Silberstein, S. (2015). Surgically implanted and non-invasive vagus nerve stimulation: a review of efficacy, safety and tolerability. Eur. J. Neurol. 22, 1260-1268. doi: 10.1111/ene.12629

Berg, K. C., Crosby, R. D., Cao, L., Crow, S. J., Engel, S. G., Wonderlich, S., et al. (2015). Negative affect prior to and following overeating-only, loss of control eating-only, and binge eating episodes in obese adults. Int. J. Eat. Disord. 48, 641-653. doi: 10.1002/eat.22401 
Beucke, J. C., Sepulcre, J., Talukdar, T., Linnman, C., Zschenderlein, K., Endrass, T., et al. (2013). Abnormally high degree connectivity of orbitofrontal cortex in obsessive-compulsive disorder. JAMA Psychiatry 70, 619-629. doi: 10.1001/jamapsychiatry.2013.173

Biezonski, D., Cha, J., Steinglass, J., and Posner, J. (2015). Evidence for thalamocortical circuit abnormalities and associated cognitive dysfunctions in underweight individuals with anorexia nervosa. Neuropsychopharmacology. doi: 10.1038/npp.2015.314. [Epub ahead of print].

Bischoff-Grethe, A., McCurdy, D., Grenesko-Stevens, E., Irvine, L. E. Z., Wagner, A., Yau, W.-Y. W., et al. (2013). Altered brain response to reward and punishment in adolescents with Anorexia nervosa. Psychiatry Res. 214, 331-340. doi: 10.1016/j.pscychresns.2013.07.004

Boehm, I., Geisler, D., King, J. A., Ritschel, F., Seidel, M., Deza Araujo, Y., et al. (2014). Increased resting state functional connectivity in the fronto-parietal and default mode network in anorexia nervosa. Front. Behav. Neurosci. 8:346. doi: 10.3389/fnbeh.2014.00346

Bohon, C., and Stice, E. (2011). Reward abnormalities among women with full and subthreshold bulimia nervosa: a functional magnetic resonance imaging study. Int. J. Eat. Disord. 44, 585-595. doi: 10.1002/eat.20869

Bohon, C., and Stice, E. (2012). Negative affect and neural response to palatable food intake in bulimia nervosa. Appetite 58, 964-970. doi: 10.1016/j.appet.2012.02.051

Broft, A., Shingleton, R., Kaufman, J., Liu, F., Kumar, D., Slifstein, M., et al. (2012). Striatal dopamine in bulimia nervosa: a PET imaging study. Int. J. Eat. Disord. 45, 648-656. doi: 10.1002/eat.20984

Brunoni, A. R., Nitsche, M. A., Bolognini, N., Bikson, M., Wagner, T., Merabet, L., et al. (2012). Clinical research with transcranial direct current stimulation (tDCS): challenges and future directions. Brain Stimul. 5, 175-195. doi: 10.1016/j.brs.2011.03.002

Bulik, C. M., Bacanu, S.-A., Klump, K. L., Fichter, M. M., Halmi, K. A., Keel, P., et al. (2005). Selection of eating-disorder phenotypes for linkage analysis. Am. J. Med. Genet. B. Neuropsychiatr. Genet. 139B, 81-87. doi: 10.1002/ajmg.b. 30227

Carpenter, L. L., Janicak, P. G., Aaronson, S. T., Boyadjis, T., Brock, D. G., Cook, I. A., et al. (2012). Transcranial magnetic stimulation (TMS) for major depression: a multisite, naturalistic, observational study of acute treatment outcomes in clinical practice. Depress. Anxiety 29, 587-596. doi: $10.1002 /$ da. 21969

Carter, J. C., Mercer-Lynn, K. B., Norwood, S. J., Bewell-Weiss, C. V., Crosby, R. D., Woodside, D. B., et al. (2012). A prospective study of predictors of relapse in anorexia nervosa: implications for relapse prevention. Psychiatry Res. 200, 518-523. doi: 10.1016/j.psychres.2012.04.037

Castellini, G., Polito, C., Bolognesi, E., D’Argenio, A., Ginestroni, A., Mascalchi, M., et al. (2013). Looking at my body. similarities and differences between anorexia nervosa patients and controls in body image visual processing. Eur. Psychiatry 28, 427-435. doi: 10.1016/j.eurpsy.2012.06.006

Celone, K. A., Thompson-Brenner, H., Ross, R. S., Pratt, E. M., and Stern, C. E. (2011). An fMRI investigation of the fronto-striatal learning system in women who exhibit eating disorder behaviors. Neuroimage 56, 1749-1757. doi: 10.1016/j.neuroimage.2011.03.026

Chan, T. W. S., Ahn, W.-Y., Bates, J. E., Busemeyer, J. R., Guillaume, S., Redgrave, G. W., et al. (2013). Differential impairments underlying decision making in anorexia nervosa and bulimia nervosa: a cognitive modeling analysis. Int. J. Eat. Disord., 47, 157-167. doi: 10.1002/eat.22223

Chen, R., Classen, J., Gerloff, C., Celnik, P., Wassermann, E. M., Hallett, M., et al. (1997). Depression of motor cortex excitability by low-frequency transcranial magnetic stimulation. Neurology 48, 1398-1403. doi: 10.1212/WNL.48. 5.1398

Chib, V. S., Yun, K., Takahashi, H., and Shimojo, S. (2013). Noninvasive remote activation of the ventral midbrain by transcranial direct current stimulation of prefrontal cortex. Transl. Psychiatry 3, e268. doi: 10.1038/tp.2013.44

Cho, J.-H., Deisseroth, K., and Bolshakov, V. Y. (2013). Synaptic encoding of fear extinction in mPFC-amygdala circuits. Neuron 80, 1491-1507. doi: 10.1016/j.neuron.2013.09.025

Cho, S. S., Ko, J. H., Pellecchia, G., Van Eimeren, T., Cilia, R., and Strafella, A. P. (2010). Continuous theta burst stimulation of right dorsolateral prefrontal cortex induces changes in impulsivity level. Brain Stimul. 3, 170-176. doi: 10.1016/j.brs.2009.10.002
Cho, S. S., Kosimori, Y., Aminian, K., Obeso, I., Rusjan, P., Lang, A., et al. (2014). Investing in the future: stimulation of the medial prefrontal cortex reduces discounting of delayed rewards. Neuropsychopharmacology. 40, 546-553. doi: 10.1038/npp.2014.211

Ciampi de Andrade, D., Galhardoni, R., Pinto, L. F., Lancelotti, R., Rosi, J., Marcolin, M. A., et al. (2012). Into the island: a new technique of noninvasive cortical stimulation of the insula. Neurophysiol. Clin. 42, 363-368. doi: 10.1016/j.neucli.2012.08.003

Claudino, A., M., Van den Eynde, F., Stahl, D., Dew, T., Andiappan, M., Kalthoff, J., et al. (2011). Repetitive transcranial magnetic stimulation reduces cortisol concentrations in bulimic disorders. Psychol. Med. 41, 1329-1336. doi: $10.1017 /$ S0033291710001881

Cowdrey, F. A., Harmer, C. J., Park, R. J., and McCabe, C. (2012). Neural responses to emotional faces in women recovered from anorexia nervosa. Psychiatry Res. 201, 190-195. doi: 10.1016/j.pscychresns.2011.08.009

Cowdrey, F. A., Park, R. J., Harmer, C. J., and McCabe, C. (2011). Increased neural processing of rewarding and aversive food stimuli in recovered anorexia nervosa. Biol. Psychiatry 70, 736-743. doi: 10.1016/j.biopsych.2011.05.028

Craig, A. D. (2002). How do you feel? Interoception: the sense of the physiological condition of the body. Nat. Rev. Neurosci. 3, 655-666. doi: 10.1038/nrn894

Crane, A., Roberts, M. E., and Treasure, J. (2007). Are obsessive-compulsive personality traits associated with a poor outcome in anorexia nervosa? A systematic review of randomized controlled trials and naturalistic. Int. J. Eat. Disord. 40, 581-588. doi: 10.1002/eat

Decker, J. H., Figner, B., and Steinglass, J. E. (2014). On weight and waiting: delay discounting in anorexia nervosa pretreatment and posttreatment. Biol. Psychiatry, 78, 606-614. doi: 10.1016/j.biopsych.2014.12.016

De Ridder, D., Vanneste, S., Kovacs, S., Sunaert, S., and Dom, G. (2011). Transient alcohol craving suppression by rTMS of dorsal anterior cingulate: an fMRI and LORETA EEG study. Neurosci. Lett. 496, 5-10. doi: 10.1016/j.neulet.2011.03.074

Dinur-Klein, L., Dannon, P., Hadar, A., Rosenberg, O., Roth, Y., Kotler, M., et al. (2014). Smoking cessation induced by deep repetitive transcranial magnetic stimulation of the prefrontal and insular cortices: a prospective, randomized controlled trial. Biol. Psychiatry 76, 742-749. doi: 10.1016/j.biopsych.2014.05.020

Donaldson, P. H., Rinehart, N. J., and Enticott, P. G. (2015). Noninvasive stimulation of the temporoparietal junction: a systematic review. Neurosci. Biobehav. Rev. 55, 547-572. doi: 10.1016/j.neubiorev.2015.05.017

Downar, J., Geraci, J., Salomons, T. V., Dunlop, K., Wheeler, S., McAndrews, M. P., et al. (2014). Anhedonia and reward-circuit connectivity distinguish nonresponders from responders to dorsomedial prefrontal repetitive transcranial magnetic stimulation in major depression. Biol. Psychiatry 76, 176-185. doi: 10.1016/j.biopsych.2013.10.026

Downar, J., Sankar, A., Giacobbe, P., Woodside, B., and Colton, P. (2012). Unanticipated rapid remission of refractory bulimia nervosa, during highdose repetitive transcranial magnetic stimulation of the dorsomedial prefrontal cortex: a case report. Front. Psychiatry 3:30. doi: 10.3389/fpsyt.2012.00030

Dunlop, J., Woodside, B., Lam, E., Olmsted, M., Colton, P., Giacobbe, P., et al. (2015). Increases in frontostriatal connectivity are associated with response to dorsomedial repetitive transcranial magnetic stimulation in refractory binge/purge behaviors. Neuroimage Clin. 8, 611-618. doi: 10.1016/j.nicl.2015.06.008

Dunlop, K., Hanlon, C. A., and Downar, J. (accepted). Non-invasive brain stimulation treatments for addiction and major depression. Ann. N.Y. Acad. Sci. Addict. Rev.

Dunlop, K., Woodside, B., Olmsted, M., Colton, P., Giacobbe, P., and Downar, J. (2015). Reductions in cortico-striatal hyperconnectivity accompany successful treatment of obsessive-compulsive disorder with dorsomedial prefrontal rTMS. Neuropsychopharmacology. doi: 10.1038/npp.2015.292. [Epub ahead of print].

Eddy, K. T., Crosby, R. D., Keel, P. K., Wonderlich, S. A., le Grange, D., Hill, L., et al. (2009). Empirical identification and validation of eating disorder phenotypes in a multisite clinical sample. J. Nerv. Ment. Dis. 197, 41-49. doi: 10.1097/NMD.0b013e3181927389

Ehrlich, S., Geisler, D., Ritschel, F., King, J., Seidel, M., Boehm, I., et al. (2015). Elevated cognitive control over reward processing in recovered female patients with anorexia nervosa. J. Psychiatry Neurosci. 40, 307-315. doi: $10.1503 /$ jpn. 140249 
Eldaief, M. C., Halko, M. A., Buckner, R. L., and Pascual-Leone, A. (2011). Transcranial magnetic stimulation modulates the brain's intrinsic activity in a frequency-dependent manner. Proc. Natl. Acad. Sci. U.S.A. 108, 21229-21234. doi: 10.1073/pnas.1113103109

Ellison, Z., Foong, J., Howard, R., Bullmore, E., Williams, S., and Treasure, J. (1998). Functional anatomy of calorie fear in anorexia nervosa. Lancet 352, 1192.

Enticott, P. G., Fitzgibbon, B. M., Kennedy, H. A., Arnold, S. L., Elliot, D., Peachey, A., et al. (2014). A double-blind, randomized trial of deep repetitive transcranial magnetic stimulation (rTMS) for autism spectrum disorder. Brain Stimul. 7, 206-211. doi: 10.1016/j.brs.2013.10.004

Enticott, P. G., Kennedy, H. A., Zangen, A., and Fitzgerald, P. B. (2011). Deep repetitive transcranial magnetic stimulation associated with improved social functioning in a young woman with an autism spectrum disorder. J. ECT 27, 41-43. doi: 10.1097/YCT.0b013e3181f07948

Felix-Ortiz, A. C., Burgos-Robles, A., Bhagat, N. D., Leppla, C. A., and Tye, K. M. (2015). Bidirectional modulation of anxiety-related and social behaviors by amygdala projections to the medial prefrontal cortex. Neuroscience. doi: 10.1016/j.neuroscience.2015.07.041. [Epub ahead of print].

Fernández-Aranda, F., Pinheiro, A. P., Thornton, L. M., Berrettini, W. H., Crow, S., Fichter, M. M., et al. (2008). Impulse control disorders in women with eating disorders. Psychiatry Res. 157, 147-157. doi: 10.1016/j.psychres.2007.02.011

Filbey, F. M., Myers, U. S., and DeWitt, S. (2012). Reward circuit function in high BMI individuals with compulsive overeating: similarities with addiction. Neuroimage 63, 1800-1806. doi: 10.1016/j.neuroimage.2012.08.073

Fladung, A.-K., Schulze, U. M. E., Schöll, F., Bauer, K., and Grön, G. (2013). Role of the ventral striatum in developing anorexia nervosa. Transl. Psychiatry 3, e315. doi: $10.1038 /$ tp. 2013.88

Fonville, L., Giampietro, V., Surguladze, S., Williams, S., and Tchanturia, K. (2014). Increased BOLD signal in the fusiform gyrus during implicit emotion processing in anorexia nervosa. Neuroimage Clin. 4, 266-273. doi: 10.1016/j.nicl.2013.12.002

Fox, M. D., Liu, H., and Pascual-Leone, A. (2013). Identification of reproducible individualized targets for treatment of depression with TMS based on intrinsic connectivity. Neuroimage 66, 151-160. doi: 10.1016/j.neuroimage.2012.10.082

Frank, G. K., Bailer, U. F., Henry, S. E., Drevets, W., Meltzer, C. C., Price, J. C., et al. (2005). Increased dopamine D2/D3 receptor binding after recovery from anorexia nervosa measured by positron emission tomography and [11C]raclopride. Biol. Psychiatry 58, 908-912. doi: 10.1016/j.biopsych.2005.05.003

Frank, G. K., Kaye, W. H., Meltzer, C. C., Price, J. C., Greer, P., McConaha, C., et al. (2002). Reduced 5-HT2A receptor binding after recovery from anorexia nervosa. Biol. Psychiatry 52, 896-906. doi: 10.1016/S0006-3223(02)01378-1

Frank, G. K., Wagner, A., Achenbach, S., McConaha, C., Skovira, K., Aizenstein, H., et al. (2006). Altered brain activity in women recovered from bulimic-type eating disorders after a glucose challenge: a pilot study. Int. J. Eat. Disord. 39, 76-79. doi: 10.1002/eat.20210

Frank, G. K. W., Reynolds, J. R., Shott, M. E., Jappe, L., Yang, T. T., Tregellas, J. R., et al. (2012a). Anorexia nervosa and obesity are associated with opposite brain reward response. Neuropsychopharmacology 37, 2031-2046. doi: 10.1038/npp.2012.51

Frank, G. K. W., Reynolds, J. R., Shott, M. E., and O’Reilly, R. C. (2011). Altered temporal difference learning in bulimia nervosa. Biol. Psychiatry 70, 728-735. doi: 10.1016/j.biopsych.2011.05.011

Frank, G. K. W., Roblek, T., Shott, M. E., Jappe, L. M., Rollin, M. D. H., Hagman, J. O., et al. (2012b). Heightened fear of uncertainty in anorexia and bulimia nervosa. Int. J. Eat. Disord. 45, 227-232. doi: 10.1002/eat.20929

Fregni, F., Orsati, F., Pedrosa, W., Fecteau, S., Tome, F. A. M., Nitsche, M. A., et al. (2008). Transcranial direct current stimulation of the prefrontal cortex modulates the desire for specific foods. Appetite 51, 34-41. doi: 10.1016/j.appet.2007.09.016

Friederich, H.-C., Brooks, S., Uher, R., Campbell, I. C., Giampietro, V., Brammer, M., et al. (2010). Neural correlates of body dissatisfaction in anorexia nervosa. Neuropsychologia 48, 2878-2885. doi: 10.1016/j.neuropsychologia.2010. 04.036

Galusca, B., Sigaud, T., Costes, N., Redoute, J., Massoubre, C., and Estour, B. (2014). Wide impairment of cerebral serotoninergic activity but inter-individual heterogeneity in bulimia nervosa patients: a pilot
[(18)F]MPPF/PET study. World J. Biol. Psychiatry 15, 599-608. doi: 10.3109/15622975.2014.942358

Garfinkel, P. E., Lin, E., Goering, P., Spegg, C., Goldbloom, D. S., Kennedy, S., et al. (1995). Bulimia nervosa in a Canadian community sample: prevalence and comparison of subgroups. Am. J. Psychiatry 152, 1052-1058.

Garrett, A., Lock, J., Datta, N., Beenhaker, J., Kesler, S. R., and Reiss, A. L. (2014). Predicting clinical outcome using brain activation associated with set-shifting and central coherence skills in anorexia nervosa. J. Psychiatr. Res. 57, 26-33. doi: 10.1016/j.jpsychires.2014.06.013

Gatt, L., Jan, S., Mondraty, N., Horsfield, S., Russell, J., Laba, T., et al. (2014). The household economic burden of eating disorders and adherence to treatment in Australia. BMC Psychiatry 29:338. doi: 10.1186/s12888-014-0338-0

Giel, K. E., Kullmann, S., Preißl, H., Bischoff, S. C., Thiel, A., Schmidt, U., et al. (2013). Understanding the reward system functioning in anorexia nervosa: crucial role of physical activity. Biol. Psychol. 94, 575-581. doi: 10.1016/j.biopsycho.2013.10.004

Giuliano, C., and Cottone, P. (2015). The role of the opioid system in binge eating disorder. CNS Spectr. 20, 537-545. doi: 10.1017/S10928529150 00668

Glashouwer, K. A., Bloot, L., Veenstra, E. M., Franken, I. H. A., and de Jong, P. J. (2014). Heightened sensitivity to punishment and reward in anorexia nervosa. Appetite 75, 97-102. doi: 10.1016/j.appet.2013.12.019

Godart, N. T., Flament, M. F., Curt, F., Perdereau, F., Lang, F., Venisse, J., et al. (2003). Anxiety disorders in subjects seeking treatment for eating disorders: a DSM-IV controlled study. Psychiatry Res. 117, 245-258. doi: 10.1016/S01651781(03)00038-6

Golden, N. H., Katzman, D. K., Kreipe, R. E., Stevens, S. L., Sawyer, S. M., Rees, J., et al. (2003). Eating disorders in adolescents: position paper of the society for adolescent medicine. J. Adolesc. Heal. 33, 496-503. doi: 10.1016/j.jadohealth.2003.08.004

Goldman, R. L., Borckardt, J. J., Frohman, H. A., O’Neil, P. M., Madan, A., Campbell, L. K., et al. (2011). Prefrontal cortex transcranial direct current stimulation (tDCS) temporarily reduces food cravings and increases the selfreported ability to resist food in adults with frequent food craving. Appetite 56, 741-746. doi: 10.1016/j.appet.2011.02.013

Gorelick, D. A., Zangen, A., and George, M. S. (2014). Transcranial magnetic stimulation in the treatment of substance addiction. Ann. N.Y. Acad. Sci. 1327, 79-93. doi: 10.1111/nyas.12479

Grall-Bronnec, M., and Sauvaget, A. (2014). The use of repetitive transcranial magnetic stimulation for modulating craving and addictive behaviours: a critical literature review of efficacy, technical and methodological considerations. Neurosci. Biobehav. Rev. 47C, 592-613. doi: 10.1016/j.neubiorev.2014.10.013

Grimonprez, A., Raedt, R., Baeken, C., Boon, P., and Vonck, K. (2015). The antidepressant mechanism of action of vagus nerve stimulation: evidence from preclinical studies. Neurosci. Biobehav. Rev. 56, 26-34. doi: 10.1016/j.neubiorev.2015.06.019

Guhn, A., Dresler, T., Andreatta, M., Müller, L. D., Hahn, T., Tupak, S. V., et al. (2014). Medial prefrontal cortex stimulation modulates the processing of conditioned fear. Front. Behav. Neurosci. 8:44. doi: 10.3389/fnbeh.2014.00044

Hallett, M. (2007). Transcranial magnetic stimulation: a primer. Neuron 55, 187-199. doi: 10.1016/j.neuron.2007.06.026

Hanlon, C. A., Canterberry, M., Taylor, J., Devries, W., and George, M. (2013). "Functional and structural integrity of frontal-striatal circuits in cocaine users: an interleaved TMS-BOLD \& DTI study," in Annual Meeting of the Society for Biological Psychiatry, Vol. 256 (San Francisco, CA).

Hanlon, C. A., Dowdle, L. T., Austelle, C. W., Devries, W., Mithoefer, O., Badran, B. W., et al. (2015). What goes up, can come down: Novel brain stimulation paradigms may attenuate craving and craving-related neural circuitry in substance dependent individuals. Brain Res. 1628(Pt A), 199-209. doi: 10.1016/ j.brainres.2015.02.053

Harrison, A., O'Brien, N., Lopez, C., and Treasure, J. (2010). Sensitivity to reward and punishment in eating disorders. Psychiatry Res. 177, 1-11. doi: 10.1016/j.psychres.2009.06.010

Hart, L. M., Granillo, M. T., Jorm, A. F., and Paxton, S. J. (2011). Unmet need for treatment in the eating disorders: a systematic review of eating disorder specific treatment seeking among community cases. Clin. Psychol. Rev. 31, 727-735. doi: 10.1016/j.cpr.2011.03.004 
Hausmann, A., Mangweth, B., Walpoth, M., Hoertnagel, C., Kramer-Reinstadler, K., Rupp, C. I., et al. (2004). Repetitive transcranial magnetic stimulation (rTMS) in the double-blind treatment of a depressed patient suffering from bulimia nervosa: a case report. Int. J. Neuropsychopharmacol. 7, 371-373. doi: $10.1017 /$ S1461145704004420

Hay, P. J., Touyz, S., and Sud, R. (2012). Treatment for severe and enduring anorexia nervosa: a review. Aust. N. Z. J. Psychiatry 42, 1136-1144. doi: $10.1177 / 0004867412450469$

Hege, M. A., Stingl, K. T., Kullmann, S., Schag, K., Giel, K. E., Zipfel, S., et al. (2014). Attentional impulsivity in binge eating disorder modulates response inhibition performance and frontal brain networks. Int. J. Obes. (Lond). 39, 353-360. doi: 10.1038/ijo.2014.99

Hilbert, A., Bishop, M. E., Stein, R. I., Tanofsky-Kraff, M., Swenson, A. K., Welch, R. R., et al. (2012). Long-term efficacy of psychological treatments for binge eating disorder. Br. J. Psychiatry 200, 232-237. doi: 10.1192/bjp.bp.110.089664

Hoffman, E. R., Gagne, D. A., Thornton, L. M., Klump, K. L., Brandt, H., Crawford, S., et al. (2012). Understanding the association of impulsivity, obsessions, and compulsions with binge eating and purging behaviours in anorexia nervosa. Eur. Eat. Disord. Rev. 20, e129-e136. doi: 10.1002/ erv.2161

Holsen, L., Lawson, E., Blum, J., Ko, E., Makris, N., Fazeli, P., et al. (2012). Food motivation circuitry hypoactivation related to hedonic and nonhedonic aspects of hunger and satiety in women with active anorexia nervosa and weightrestored women with anorexia nervosa. J. Psychiatry Neurosci. 37, 322-232. doi: 10.1503/jpn.110156

Holtzheimer, P. E., McDonald, W. M., Mufti, M., Kelley, M. E., Quinn, S., Corso, G., et al. (2010). Accelerated repetitive transcranial magnetic stimulation for treatment-resistant depression. Depress. Anxiety 27, 960-963. doi: $10.1002 /$ da. 20731

Huang, Y.-Z., Edwards, M. J., Rounis, E., Bhatia, K. P., and Rothwell, J. C. (2005). Theta burst stimulation of the human motor cortex. Neuron 45, 201-206. doi: 10.1016/j.neuron.2004.12.033

Hudson, J. I., Hiripi, E., Pope, H. G., and Kessler, R. C. (2007). The prevalence and correlates of eating disorders in the National Comorbidity Survey Replication. Biol. Psychiatry 61, 348-358. doi: 10.1016/j.biopsych.2006.03.040

Hummel, D., Rudolf, A. K., Brandi, M.-L., Untch, K.-H., Grabhorn, R., Hampel, H., et al. (2013). Neural adaptation to thin and fat bodies in the fusiform body area and middle occipital gyrus: an fMRI adaptation study. Hum. Brain Mapp. 34, 3233-3246. doi: 10.1002/hbm.22135

Insel, T., Cuthbert, B., Garvey, M., Heinssen, R., Pine, D. S., Quinn, K., et al. (2010). Research domain criteria (RDoC): toward a new classification framework for research on mental disorders. Am. J. Psychiatry 167, 748-751. doi: 10.1176/appi.ajp.2010.09091379

Isserles, M., Shalev, A. Y., Roth, Y., Peri, T., Kutz, I., Zlotnick, E., et al. (2013). Effectiveness of deep transcranial magnetic stimulation combined with a brief exposure procedure in post-traumatic stress disorder-a pilot study. Brain Stimul. 6, 377-383. doi: 10.1016/j.brs.2012.07.008

Johnstone, T., van Reekum, C. M., Urry, H. L., Kalin, N. H., and Davidson, R. J. (2007). Failure to regulate: counterproductive recruitment of top-down prefrontal-subcortical circuitry in major depression. J. Neurosci. 27, 8877-8884. doi: 10.1523/JNEUROSCI.2063-07.2007

Keating, C., Tilbrook, A. J., Rossell, S. L., Enticott, P. G., and Fitzgerald, P. B. (2012). Reward processing in anorexia nervosa. Neuropsychologia 50, 567-575. doi: 10.1016/j.neuropsychologia.2012.01.036

Keel, P. K., Fichter, M., Quadflieg, N., Bulik, C. M., Baxter, M. G., Thornton, L., et al. (2004). Application of a latent class analysis to empirically define eating disorder phenotypes. Arch. Gen. Psychiatry 61, 192-200. doi: 10.1001/archpsyc.61.2.192

Keel, P. K., and Mitchell, J. E. (1997). Outcome in bulimia nervosa. Am. J. Psychiatry 154, 313-321. doi: 10.1176/ajp.154.3.313

Kekic, M., McClelland, J., Campbell, I., Nestler, S., Rubia, K., David, A. S., et al. (2014). The effects of prefrontal cortex transcranial direct current stimulation (tDCS) on food craving and temporal discounting in women with frequent food cravings. Appetite 78, 55-62. doi: 10.1016/j.appet.2014.03.010

Kerr, K., Moseman, S., Avery, J., Bodurka, J., Zucker, N., and Kyle Simmons, W. (2015). Altered insula activity during visceral interoception in weight-restored patients with anorexia nervosa. Neuropsychopharmacology. 41, 521-528. doi: 10.1038/npp.2015.174
Khedr, E., Elfetoh, N., Ali, A., and Noamany, M. (2014). Anodal transcranial direct current stimulation over the dorsolateral prefrontal cortex improves anorexia nervosa: a pilot study. Restor. Neurol. Neurosci. 32, 789-797. doi: 10.3233/RNN-140392

Klein, D. A., Schebendach, J. E., Gershkovich, M., Bodell, L., Foltin, R., and Walsh, B. T. (2010). Behavioral assessment of the reinforcing effect of exercise in women with anorexia nervosa: further paradigm development and data. Int. J. Eat. Disord. 43, 611-618. doi: 10.1002/eat.20758

Kozel, F. A., Nahas, Z., deBrux, C., Molloy, M., Lorberbaum, J. P., Bohning, D., et al. (2000). How coil-cortex distance relates to age, motor threshold, and antidepressant response to repetitive transcranial magnetic stimulation. J. Neuropsychiatry Clin. Neurosci. 12, 376-384. doi: 10.1176/appi.neuropsych.12.3.376

Kühn, S., Gallinat, J., and Brass, M. (2011). "Keep Calm and Carry On”: structural correlates of expressive suppression of emotions. PLoS ONE 6:e16569. doi: 10.1371/journal.pone.0016569

Kullmann, S., Giel, K. E., Hu, X., Bischoff, S. C., Teufel, M., Thiel, A., et al. (2014). Impaired inhibitory control in anorexia nervosa elicited by physical activity stimuli. Soc. Cogn. Affect. Neurosci. 9, 917-923. doi: 10.1093/scan/ nst070

Lao-Kaim, N., Fonville, L., Giampietro, V., Williams, S., Simmons, A., and Tchanturia, K. (2015). Aberrant function of learning and cognitive control networks underlie inefficient cognitive flexibility in anorexia nervosa: a cross-sectional fMRI study. PLoS ONE 10:e124027. doi: 10.1371/journal.pone.0124027

Lapenta, O. M., Sierve, K., de Macedo, E. C., Fregni, F., and Boggio, P. S. (2014). Transcranial direct current stimulation modulates ERP-indexed inhibitory control and reduces food consumption. Appetite 83, 42-48. doi: 10.1016/j.appet.2014.08.005

Lee, S., Ran Kim, K., Ku, J., Lee, J. H., Namkoong, K., and Jung, Y. C. (2014). Resting-state synchrony between anterior cingulate cortex and precuneus relates to body shape concern in anorexia nervosa and bulimia nervosa. Psychiatry Res. 221, 43-48. doi: 10.1016/j.pscychresns.2013.11.004

Leehr, E. J., Krohmer, K., Schag, K., Dresler, T., Zipfel, S., and Giel, K. E. (2015). Emotion regulation model in binge eating disorder and obesity-a systematic review. Neurosci. Biobehav. Rev. 49, 125-134. doi: 10.1016/j.neubiorev.2014.12.008

Li, C.-T., Chen, M.-H., Juan, C.-H., Huang, H.-H., Chen, L.-F., Hsieh, J.C., et al. (2014). Efficacy of prefrontal theta-burst stimulation in refractory depression: a randomized sham-controlled study. Brain 137, 2088-2098. doi: 10.1093/brain/awu109

Lilenfeld, L. R., Kaye, W. H., Greeno, C. G., Merikangas, K. R., Plotnicov, K., Pollice, C., et al. (1998). A controlled family study of anorexia nervosa and bulimia nervosa: psychiatric disorders in first-degree relatives and effects of proband comorbidity. Arch. Gen. Psychiatry 55, 603-610. doi: 10.1001/archpsyc.55.7.603

Lindquist, K. A., Satpute, A. B., Wager, T. D., Weber, J., and Barrett, L. F. (2015). The brain basis of positive and negative affect: evidence from a meta-analysis of the human neuroimaging literature. Cereb. Cortex. doi: 10.1093/cercor/bhv001. [Epub ahead of print].

Lipsman, N., Woodside, D. B., Giacobbe, P., Hamani, C., Carter, J. C., Norwood, S. J., et al. (2013). Subcallosal cingulate deep brain stimulation for treatmentrefractory anorexia nervosa: a phase 1 pilot trial. Lancet 381, 1361-1370. doi: 10.1016/S0140-6736(12)62188-6

Lock, J., Garrett, A., Beenhakker, J., and Reiss, A. L. (2011). Aberrant brain activation during a response inhibition task in adolescent eating disorder subtypes. Am. J. Psychiatry 168, 55-64. doi: 10.1176/appi.ajp.2010.10010056

Luo, Y., Qin, S., Fernández, G., Zhang, Y., Klumpers, F., and Li, H. (2014). Emotion perception and executive control interact in the salience network during emotionally charged working memory processing. Hum. Brain Mapp. 35, 5606-5616. doi: 10.1002/hbm.22573

Machii, K., Cohen, D., Ramos-Estebanez, C., and Pascual-Leone, A. (2006). Safety of rTMS to non-motor cortical areas in healthy participants and patients. Clin. Neurophysiol. 117, 455-471. doi: 10.1016/j.clinph.2005.10.014

Maeda, F., Keenan, J. P., Tormos, J. M., Topka, H., and Pascual-Leone, A. (2000). Interindividual variability of the modulatory effects of repetitive transcranial magnetic stimulation on cortical excitability. Exp. Brain Res. 133, 425-430. doi: $10.1007 / \mathrm{s} 002210000432$ 
Mantovani, A., Simpson, H. B., Fallon, B. A., Rossi, S., and Lisanby, S. H. (2010). Randomized sham-controlled trial of repetitive transcranial magnetic stimulation in treatment-resistant obsessive-compulsive disorder. Int. J. Neuropsychopharmacol. 13, 217-227. doi: 10.1017/S146114570 9990435

Manwaring, J. L., Green, L., Myerson, J., Strube, M. J., and Wilfley, D. E. (2011). Discounting of Various types of rewards by women with and without binge eating disorder: evidence for general rather than specific differences. Psychol. Rec. 61, 561-582.

Marsh, R., Horga, G., Wang, Z., Wang, P., Klahr, K. W., Berner, L. A., et al. (2011). An fMRI study of self-regulatory control and conflict resolution in adolescents with bulimia nervosa. Am. J. Psychiatry 168, 1210-1220. doi: 10.1176/appi.ajp.2011.11010094

Marsh, R., Steinglass, J. E., Gerber, A. J., Graziano O’Leary, K., Wang, Z., Murphy, D., et al. (2009). Deficient activity in the neural systems that mediate selfregulatory control in bulimia nervosa. Arch. Gen. Psychiatry 66, 51-63. doi: 10.1001/archgenpsychiatry.2008.504

McAdams, C. J., and Krawczyk, D. C. (2011). Impaired neural processing of social attribution in anorexia nervosa. Psychiatry Res. 194, 54-63. doi: 10.1016/j.pscychresns.2011.06.016

McAdams, C. J., Lohrenz, T., and Montague, P. R. (2015). Neural responses to kindness and malevolence differ in illness and recovery in women with anorexia nervosa. Hum. Brain Mapp. 36, 5207-5219. doi: 10.1002/hbm.23005

McClelland, J., Bozhilova, N., Campbell, I., and Schmidt, U. (2013). A systematic review of the effects of neuromodulation on eating and body weight: evidence from human and animal studies. Eur. Eat. Disord. Rev. 21, 436-455. doi: 10.1002/erv.2256

McClelland, J., Kekic, M., Campbell, I. C., and Schmidt, U. (2016). Repetitive transcranial magnetic stimulation (rTMS) treatment in enduring anorexia nervosa: a case series. Eur. Eat. Disord. Rev. 24, 157-163. doi: 10.1002/ erv. 2414

Meng, Z., Liu, C., Yu, C., and Ma, Y. (2014). Transcranial direct current stimulation of the frontal-parietal-temporal area attenuates smoking behavior. J. Psychiatr. Res. 54, 19-25. doi: 10.1016/j.jpsychires.2014.03.007

Meron, D., Hedger, N., Garner, M., and Baldwin, D. S. (2015). Transcranial direct current stimulation (tDCS) in the treatment of depression: systematic review and meta-analysis of efficacy and tolerability. Neurosci. Biobehav. Rev. 57, 46-62. doi: 10.1016/j.neubiorev.2015.07.012

Milos, G., Spindler, A., Schnyder, U., and Fairburn, C. G. (2005). Instability of eating disorder diagnoses: prospective study. Br. J. Psychiatry 187, 573-578. doi: 10.1192/bjp.187.6.573

Mischoulon, D., Eddy, K. T., Keshaviah, A., Dinescu, D., Ross, S. L., Kass, A. E., et al. (2011). Depression and eating disorders: treatment and course. J. Affect. Disord. 130, 470-477. doi: 10.1016/j.jad.2010.10.043

Mishra, B. R., Nizamie, S. H., Das, B., and Praharaj, S. K. (2010). Efficacy of repetitive transcranial magnetic stimulation in alcohol dependence: a shamcontrolled study. Addiction 105, 49-55. doi: 10.1111/j.1360-0443.2009.02777.x

Mitchell, J. E., Agras, S., and Wonderlich, S. (2007). Treatment of bulimia nervosa: where are we and where are we going? Int. J. Eat. Disord. 40, 95-101. doi: 10.1002/eat.20343

Miyake, Y., Okamoto, Y., Onoda, K., Shirao, N., Mantani, T., and Yamawaki, S. (2009). Neural correlates of alexithymia in response to emotional stimuli: a study of anorexia nervosa patients. Hiroshima J. Med. Sci. 58, 1-8.

Miyake, Y., Okamoto, Y., Onoda, K., Shirao, N., Okamoto, Y., Otagaki, Y., et al. (2010). Neural processing of negative word stimuli concerning body image in patients with eating disorders: an fMRI study. Neuroimage 50, 1333-1339. doi: 10.1016/j.neuroimage.2009.12.095

Miyake, Y., Okamoto, Y., Onoda, K., Shirao, N., Okamoto, Y., and Yamawaki, S. (2012). Brain activation during the perception of stressful word stimuli concerning interpersonal relationships in anorexia nervosa patients with high degrees of alexithymia in an fMRI paradigm. Psychiatry Res. 201, 113-119. doi: 10.1016/j.pscychresns.2011.07.014

Mole, T. B., Irvine, M., A., Worbe, Y., Collins, P., Mitchell, S. P., Bolton, S., et al. (2015). Impulsivity in disorders of food and drug misuse. Psychol. Med. 45, 771-782. doi: 10.1017/S0033291714001834

Morris, S. E., and Cuthbert, B. N. (2012). Research Domain Criteria: cognitive systems, neural circuits, and dimensions of behavior. Dialogues Clin. Neurosci. $14,29-37$
Nauczyciel, C., and Drapier, D. (2012). Repetitive transcranial magnetic stimulation in the treatment of obsessive-compulsive disorder. Rev. Neurol. (Paris). 168, 655-661. doi: 10.1016/j.neurol.2012. 05.006

Nettekoven, C., Volz, L. J., Leimbach, M., Pool, E.-M., Rehme, A. K., Eickhoff, S. B., et al. (2015). Inter-individual variability in cortical excitability and motor network connectivity following multiple blocks of rTMS. Neuroimage 118, 209-218. doi: 10.1016/j.neuroimage.2015.06.004

Nitsche, M. A., Koschack, J., Pohlers, H., Hullemann, S., Paulus, W., and Happe, S. (2012). Effects of frontal transcranial direct current stimulation on emotional state and processing in healthy humans. Front. Psychiatry 3:58. doi: 10.3389/fpsyt.2012.00058

Oberndorfer, T. A., Frank, G. K. W., Simmons, A. N., Wagner, A., McCurdy, D., Fudge, J. L., et al. (2013a). Altered insula response to sweet taste processing after recovery from anorexia and bulimia nervosa. Am. J. Psychiatry 170, 1143-1151. doi: 10.1176/appi.ajp.2013.11111745

Oberndorfer, T. A., Kaye, W. H., Simmons, A. N., Strigo, I. A., and Matthews, S. C. (2011). Demand-specific alteration of medial prefrontal cortex response during an inhibition task in recovered anorexic women. Int. J. Eat. Disord. 44, 1-8. doi: 10.1002/eat. 20750

Oberndorfer, T., Simmons, A., McCurdy, D., Strigo, I., Matthews, S., Yang, T., et al. (2013b). Greater anterior insula activation during anticipation of food images in women recovered from anorexia nervosa versus controls. Psychiatry Res. 214, 132-141. doi: 10.1016/j.pscychresns.2013.06.010

Olmsted, M. P., Kaplan, A. S., and Rockert, W. (2005). Defining remission and relapse in bulimia nervosa. Int. J. Eat. Disord. 38, 1-6. doi: 10.1002/eat.20144

Pascual-Leone, A., Tormos, J. M., Keenan, J., Tarazona, F., Cañete, C., and Catalá, M. D. (1998). Study and modulation of human cortical excitability with transcranial magnetic stimulation. J. Clin. Neurophysiol. 15, 333-343.

Pascual-Leone, A., Valls-Solé, J., Wassermann, E. M., and Hallett, M. (1994). Responses to rapid-rate transcranial magnetic stimulation of the human motor cortex. Brain 117(Pt 4), 847-858. doi: 10.1093/brain/117.4.847

Racine, S. E., Burt, S. A., Keel, P. K., Sisk, C. L., Neale, M. C., Boker, S., et al. (2015). Examining associations between negative urgency and key components of objective binge episodes. Int. J. Eat. Disord. 48, 527-531. doi: 10.1002/eat.22412

Radeloff, D., Willmann, K., Otto, L., Lindner, M., Putnam, K., Leeuwen, S., et al. (2012). High-fat taste challenge reveals altered striatal response in women recovered from bulimia nervosa: a pilot study. World J. Biol. Psychiatry, 15, 307-316. doi: 10.3109/15622975.2012.671958

Reineberg, A. E., Andrews-Hanna, J. R., Depue, B. E., Friedman, N. P., and Banich, M. T. (2015). Resting-state networks predict individual differences in common and specific aspects of executive function. Neuroimage 104, 69-78. doi: 10.1016/j.neuroimage.2014.09.045

Ritschel, F., King, J. A., Geisler, D., Flohr, L., Neidel, F., Boehm, I., et al. (2015). Temporal delay discounting in acutely ill and weightrecovered patients with anorexia nervosa. Psychol. Med. 45, 1229-1239. doi: $10.1017 /$ S0033291714002311

Rossi, S., and Hallett, M. (2009). Safety, ethical considerations, and application guidelines for the use of transcranial magnetic stimulation in clinical practice and research. Clin. Neurophysiol. 120, 2008-2039. doi: 10.1016/j.clinph.2009.08.016

Roth, Y., Amir, A., Levkovitz, Y., and Zangen, A. (2007). Three-dimensional distribution of the electric field induced in the brain by transcranial magnetic stimulation using figure-8 and deep H-coils. J. Clin. Neurophysiol. 24, 31-38. doi: 10.1097/WNP.0b013e31802fa393

Roth, Y., Levkovitz, Y., Pell, G. S., Ankry, M., and Zangen, A. (2014). Safety and characterization of a novel multi-channel TMS stimulator. Brain Stimul. 7, 194-205. doi: 10.1016/j.brs.2013.09.004

Rothemund, Y., Buchwald, C., Georgiewa, P., Bohner, G., Bauknecht, H. C., Ballmaier, M., et al. (2011). Compulsivity predicts fronto striatal activation in severely anorectic individuals. Neuroscience 197, 242-250. doi: 10.1016/j.neuroscience.2011.09.016

Salomons, T. V., Dunlop, K., Kennedy, S. H., Flint, A., Geraci, J., Giacobbe, P., et al. (2014). Resting-state cortico-thalamic-striatal connectivity predicts response to dorsomedial prefrontal rTMS in major depressive disorder. Neuropsychopharmacology 39, 488-498. doi: 10.1038/npp.2013.222

Sanders, N., Smeets, P., van Elburg, A., Danner, U., van Meer, F., Hoek, H., et al. (2015). Altered food-cue processing in chronically ill and 
recovered women with anorexia nervosa. Front. Behav. Neurosci. 9:46. doi: 10.3389/fnbeh.2015.00046

Sato, Y., Saito, N., Utsumi, A., Aizawa, E., Shoji, T., Izumiyama, M., et al. (2013). Neural basis of impaired cognitive flexibility in patients with anorexia nervosa. PLoS ONE 8:e61108. doi: 10.1371/journal.pone.0061108

Saxe, R., and Kanwisher, N. (2003). People thinking about thinking people. The role of the temporo-parietal junction in "theory of mind." Neuroimage 19, 1835-1842. doi: 10.1016/S1053-8119(03)00230-1

Schebendach, J., Broft, A., Foltin, R., and Walsh, B. T. (2013). Can the reinforcing value of food be measured in bulimia nervosa? Appetite 62, 70-75. doi: 10.1016/j.appet.2012.11.009

Schebendach, J. E., Klein, D. A., Foltin, R. W., Devlin, M. J., and Walsh, B. T. (2007). Relative reinforcing value of exercise in inpatients with anorexia nervosa: model development and pilot data. Int. J. Eat. Disord. 40, 446-453. doi: 10.1002/eat.20392

Schienle, A., Schäfer, A., Hermann, A., and Vaitl, D. (2009). Binge-Eating disorder: reward sensitivity and brain activation to images of food. Biol. Psychiatry 65, 654-661. doi: 10.1016/j.biopsych.2008.09.028

Schutter, D. J. L. G., and van Honk, J. (2006). A standardized motor threshold estimation procedure for transcranial magnetic stimulation research. J. ECT 22, 176-178. doi: 10.1097/01.yct.0000235924.60364.27

Seeger, G., Braus, D. F., Ruf, M., Goldberger, U., and Schmidt, M. H. (2002). Body image distortion reveals amygdala activation in patients with anorexia nervosa - a functional magnetic resonance imaging study. Neurosci. Lett. 326, 25-28. doi: 10.1016/S0304-3940(02)00312-9

Shapiro, J. R., Berkman, N. D., Brownley, K. A., Sedway, J. A., Lohr, K. N., and Bulik, C. M. (2007). Bulimia nervosa treatment: a systematic review of randomized controlled trials. Int. J. Eat. Disord. 40, 321-336. doi: 10.1002/eat

Smink, F. R. E., Van Hoeken, D., Oldehinkel, A. J., and Hoek, H. W. (2014). Prevalence and severity of DSM-5 eating disorders in a community cohort of adolescents. Int. J. Eat. Disord. 47, 610-619. doi: 10.1002/eat.22316

Solvason, H. B., Husain, M., Fitzgerald, P. B., Rosenquist, P., McCall, W. V., Kimball, J., et al. (2014). Improvement in quality of life with left prefrontal transcranial magnetic stimulation in patients with pharmacoresistant major depression: acute and six month outcomes. Brain Stimul. 7, 219-225. doi: 10.1016/j.brs.2013.10.008

Spangler, D. L., and Allen, M. D. (2012). An fMRI investigation of emotional processing of body shape in bulimia nervosa. Int. J. Eat. Disord. 45, 17-25. doi: 10.1002/eat.20899

Steinglass, J. E., Figner, B., Berkowitz, S., Simpson, H. B., Weber, E. U., and Walsh, B. T. (2012). Increased capacity to delay reward in anorexia nervosa. J. Int. Neuropsychol. Soc. 18, 773-780. doi: 10.1017/S1355617712000446

Steinhausen, H.-C., and Weber, S. (2009). The outcome of bulimia nervosa: findings from one-quarter century of research. Am. J. Psychiatry 166, 1331-1341. doi: 10.1176/appi.ajp.2009.09040582

Striegel-Moore, R. H., Franko, D. L., Thompson, D., Barton, B., Schreiber, G. B., and Daniels, S. R. (2005). An empirical study of the typology of bulimia nervosa and its spectrum variants. Psychol. Med. 35, 1563-1572. doi: 10.1017/S0033291705006057

Strigo, I. A., Matthews, S. C., Simmons, A. N., Oberndorfer, T., Klabunde, M., Reinhardt, L. E., et al. (2013). Altered insula activation during pain anticipation in individuals recovered from anorexia nervosa: evidence of interoceptive dysregulation. Int. J. Eat. Disord. 46, 23-33. doi: 10.1002/eat.22045

Strober, M., Freeman, R., Lampert, C., Diamond, J., and Kaye, W. (2000). Controlled family study of anorexia nervosa and bulimia nervosa: evidence of shared liability and transmission of partial syndromes. Am. J. Psychiatry 157, 393-401. doi: 10.1176/appi.ajp.157.3.393

Suchan, B., Bauser, D. S., Busch, M., Schulte, D., Grönemeyer, D., Herpertz, S., et al. (2013). Reduced connectivity between the left fusiform body area and the extrastriate body area in anorexia nervosa is associated with body image distortion. Behav. Brain Res. 241, 80-85. doi: 10.1016/j.bbr.2012.12.002

Suda, M., Brooks, S. J., Giampietro, V., Friederich, H. C., Uher, R., Brammer, M. J., et al. (2013). Functional neuroanatomy of body checking in people with anorexia nervosa. Int. J. Eat. Disord. 46, 653-662. doi: 10.1002/eat. 22150

Suda, M., Brooks, S. J., Giampietro, V., Uher, R., Mataix-Cols, D., Brammer, M. J., et al. (2014). Provocation of symmetry/ordering symptoms in
Anorexia nervosa: a functional neuroimaging study. PLoS ONE 9:e97998. doi: 10.1371/journal.pone.0097998

Sullivan, P. F. (1995). Mortality in anorexia nervosa. Am. J. Psychiatry 152, 1073-1074.

Sullivan, P. F., Bulik, C. M., and Kendler, K. S. (1998). The epidemiology and classification of bulimia nervosa. Psychol. Med. 28, 599-610. doi: 10.1017/S0033291798006576

Sutoh, C., Koga, Y., Kimura, H., Kanahara, N., Numata, N., Hirano, Y., et al. (2016). Repetitive transcranial magnetic stimulation changes cerebral oxygenation on the left dorsolateral prefrontal cortex in bulimia nervosa: a near-infrared spectroscopy pilot study. Eur. Eat. Disord. Rev. 24, 83-88. doi: 10.1002/erv.2413

Tapajóz P de Sampaio, F., Soneira, S., Aulicino, A., Harris, P., and Allegri, R. F. (2015). Emotional reactivity to social stimuli in patients with eating disorders. Psychiatry Res. 229, 887-894. doi: 10.1016/j.psychres.2015.07.049

Torresan, R. C., Ramos-Cerqueira, A. T. A., Shavitt, R. G., do Rosário, M. C., de Mathis, M. A., Miguel, E. C., et al. (2013). Symptom dimensions, clinical course and comorbidity in men and women with obsessive-compulsive disorder. Psychiatry Res. 209, 186-195. doi: 10.1016/j.psychres.2012.12.006

Tsutsumi, R., Hanajima, R., Terao, Y., Shirota, Y., Ohminami, S., Shimizu, T., et al. (2014). Effects of the motor cortical quadripulse transcranial magnetic stimulation (QPS) on the contralateral motor cortex and interhemispheric interactions. J. Neurophysiol. 111, 26-35. doi: 10.1152/jn.00515.2013

Uher, R., Murphy, T., Brammer, M. J., Dalgleish, T., Phillips, M. L., Ng, V. W., et al. (2004). Medial prefrontal cortex activity associated with symptom provocation in eating disorders. Am. J. Psychiatry 161, 1238-1246. doi: 10.1176/appi.ajp.161.7.1238

Uher, R., Yoganathan, D., Mogg, A., Eranti, S. V., Treasure, J., Campbell, I. C., et al. (2005). Effect of left prefrontal repetitive transcranial magnetic stimulation on food craving. Biol. Psychiatry 58, 840-842. doi: 10.1016/j.biopsych.2005.05.043

Ursu, S., Clark, K. A., Stenger, V. A., and Carter, C. S. (2008). Distinguishing expected negative outcomes from preparatory control in the human orbitofrontal cortex. Brain Res. 1227, 110-119. doi: 10.1016/j.brainres.2008.06.033

Val-Laillet, D., Aarts, E., Weber, B., Ferrari, M., Quaresima, V., Stoeckel, L. E., et al. (2015). Neuroimaging and neuromodulation approaches to study eating behavior and prevent and treat eating disorders and obesity. NeuroImage. Clin. 8, 1-31. doi: 10.1016/j.nicl.2015.03.016

Van den Eynde, F., Claudino, A. M., Mogg, A., Horrell, L., Stahl, D., Ribeiro, W., et al. (2010). Repetitive transcranial magnetic stimulation reduces cueinduced food craving in bulimic disorders. Biol. Psychiatry 67, 793-795. doi: 10.1016/j.biopsych.2009.11.023

Van den Eynde, F., Guillaume, S., Broadbent, H., Campbell, I. C., and Schmidt, U. (2013). Repetitive transcranial magnetic stimulation in anorexia nervosa: a pilot study. Eur. Psychiatry 28, 98-101. doi: 10.1016/j.eurpsy.2011.06.002

Via, E., Soriano-Mas, C., Sánchez, I., Forcano, L., Harrison, B. J., Davey, C. G., et al. (2015). Abnormal social reward responses in anorexia nervosa: an fMRI study. PLoS ONE 10:e0133539. doi: 10.1371/journal.pone.0133539

Vocks, S., Busch, M., Grönemeyer, D., Schulte, D., Herpertz, S., and Suchan, B. (2010). Neural correlates of viewing photographs of one's own body and another woman's body in anorexia and bulimia nervosa: an fMRI study. J. Psychiatry Neurosci. 35, 163-176. doi: 10.1503/jpn.090048

Vocks, S., Herpertz, S., Rosenberger, C., Senf, W., and Gizewski, E. R. (2011). Effects of gustatory stimulation on brain activity during hunger and satiety in females with restricting-type anorexia nervosa: an fMRI study. J. Psychiatr. Res. 45, 395-403. doi: 10.1016/j.jpsychires.2010.07.012

Voss, U., Holzmann, R., Hobson, A., Paulus, W., Koppehele-Gossel, J., Klimke, A., et al. (2014). Induction of self awareness in dreams through frontal low current stimulation of gamma activity. Nat. Neurosci. 17, 810-812. doi: 10.1038/nn.3719

Wagner, A., Aizenstein, H., Mazurkewicz, L., Fudge, J., Frank, G. K., Putnam, K., et al. (2008). Altered insula response to taste stimuli in individuals recovered from restricting-type anorexia nervosa. Neuropsychopharmacology 33, 513-523. doi: 10.1038/sj.npp.1301443

Wagner, A., Aizenstein, H., Venkatraman, V. K., Fudge, J., May, J. C., Mazurkewicz, L., et al. (2007). Altered reward processing in women recovered from anorexia nervosa. Am. J. Psychiatry 164, 1842-1849. doi: 10.1176/appi.ajp.2007.07040575 
Walpoth, M., Hoertnagl, C., Mangweth-Matzek, B., Kemmler, G., Hinterhölzl, J., Conca, A., et al. (2008). Repetitive transcranial magnetic stimulation in bulimia nervosa: preliminary results of a single-centre, randomised, doubleblind, sham-controlled trial in female outpatients. Psychother. Psychosom. 77, 57-60. doi: 10.1159/000110061

Walsh, B. T. (2013). The enigmatic persistence of anorexia nervosa. Am. J. Psychiatry 170, 477-484. doi: 10.1176/appi.ajp.2012.12081074

Weygandt, M., Schaefer, A., Schienle, A., and Haynes, J. D. (2012). Diagnosing different binge-eating disorders based on reward-related brain activation patterns. Hum. Brain Mapp. 33, 2135-2146. doi: 10.1002/hbm.21345

Wierenga, C. E., Ely, A., Bischoff-Grethe, A., Bailer, U. F., Simmons, A. N., and Kaye, W. H. (2014). Are extremes of consumption in eating disorders related to an altered balance between reward and inhibition? Front. Behav. Neurosci. 8:410. doi: $10.3389 /$ fnbeh. 2014.00410

Wiethoff, S., Hamada, M., and Rothwell, J. C. (2014). Variability in response to transcranial direct current stimulation of the motor cortex. Brain Stimul. 7, 468-475. doi: 10.1016/j.brs.2014.02.003

Wildes, J. E., Forbes, E. E., and Marcus, M. D. (2014). Advancing research on cognitive flexibility in eating disorders: the importance of distinguishing attentional set-shifting and reversal learning. Int. J. Eat. Disord. 47, 227-230. doi: 10.1002/eat.22243

Wildes, J. E., Forbush, K. T., and Markon, K. E. (2013). Characteristics and stability of empirically derived anorexia nervosa subtypes: towards the identification of homogeneous low-weight eating disorder phenotypes. J. Abnorm. Psychol. 122, 1031-1041. doi: 10.1037/a0034676
Wildes, J., and Marcus, M. (2015). Application of the Research Domain Criteria (RDoC) framework to eating disorders: emerging concepts and research. Curr. Psychiatry Rep. 17, 1-10. doi: 10.1007/s11920-015-0572-2

Wonderlich, S. A., Crosby, R. D., Joiner, T., Peterson, C. B., Bardone-Cone, A., Klein, M., et al. (2005). Personality subtyping and bulimia nervosa: psychopathological and genetic correlates. Psychol. Med. 35, 649-657. doi: $10.1017 /$ S0033291704004234

Wu, M., Hartmann, M., Skunde, M., Herzog, W., and Friederich, H.-C. (2013). Inhibitory control in bulimic-type eating disorders: a systematic review and meta-analysis. PLoS ONE 8:e83412. doi: 10.1371/journal.pone.0083412

Zastrow, A., Kaiser, S., Stippich, C., Walther, S., Herzog, W., Tchanturia, K., et al. (2009). Neural correlates of impaired cognitive-behavioral flexibility in anorexia nervosa. Am. J. Psychiatry 166, 608-616. doi: 10.1176/appi.ajp.2008.08050775

Conflict of Interest Statement: The authors declare that the research was conducted in the absence of any commercial or financial relationships that could be construed as a potential conflict of interest.

Copyright $\odot 2016$ Dunlop, Woodside and Downar. This is an open-access article distributed under the terms of the Creative Commons Attribution License (CC BY). The use, distribution or reproduction in other forums is permitted, provided the original author(s) or licensor are credited and that the original publication in this journal is cited, in accordance with accepted academic practice. No use, distribution or reproduction is permitted which does not comply with these terms. 